\title{
Tempo e Espaço Guarani: um estudo acerca da ocupação, cronologia e dinâmica de movimentação pré-colonial na Bacia do Rio Taquari/Antas, Rio Grande do Sul, Brasil Guarani Space and Time: a study about occupation, chronology and pre-colonial migration dynamics in the Taquari/Antas River Basin, Rio Grande do Sul, Brazil
}

\author{
Fernanda Schneider', Sidnei Wolf', Marcos Rogério Kreutz', Neli Teresinha Galarce Machado' \\ 'Centro Universitário Univates. Lajeado, Rio Grande do Sul, Brasil
}

\begin{abstract}
Resumo: Neste artigo foram analisadas as relações espaciais e temporais da ocupação Guarani pré-colonial na Bacia do Rio Taquari/Antas a partir da delimitação do perímetro da ocupação e seu estabelecimento na paisagem, da cronologia intrasítio e regional e de discussões referentes às movimentações espaciais. A partir dos resultados foram mapeados 121 sítios Guarani na porção centro-sul da Bacia, em um perímetro de várzeas que circundou as terras altas do Planalto das Araucárias, demonstrando tratar-se de uma ocupação regional longa, entre os séculos XIV e XVIII. O estabelecimento teria ocorrido a partir da conexão entre o Rio Jacuí e o Rio Taquari/Antas, em uma expansão compulsória do sul para o norte, observando-se assentamentos contemporâneos em todo o perímetro e sítios com fatores de alta permanência. Tal dinâmica justificar-se-ia a partir de um controle consciente do ambiente, permitindo, por um lado, a manutenção das aldeias, e, por outro, o crescimento demográfico e novas expansões. Além da motivação demográfica, inferiu-se a possibilidade de que os limites da ocupação Guarani na região tenham sido estabelecidos de forma igualmente consciente a partir de um pulso de expansão inicial e posterior estabilidade, configurando-se a ocupação compulsória como uma estratégia de manutenção política do território.
\end{abstract}

Palavras-chave: Arqueologia Guarani. Terras baixas da América do Sul. Bacia do Rio Taquari/Antas. Análise espacial. Cronologia.

Abstract: This study examines spatial and temporal relations of pre-colonial Guarani occupation in the Taquari/Antas River Basin. The perimeter of occupation and itsestablishment inthe landscapeare discussedas well as local and regional chronology and migrations. The data wereused to map 121 Guarani sites in the center-south portion of the river basin, in a perimeter of lowlands surrounding the highlands of the Plateau of the Araucarias. Results show that therewas a long regional occupation between the $14^{\text {th }}$ and $18^{\text {th }}$ centuries. The Guarani settlementsin this region occurred at the confluenceof the Jacuí and Taquari/Antasrivers, in a forcedexpansion from south to north, where contemporary settlements can be observed throughout the perimeter, and sites show evidence of longpermanence. Such dynamics can be understood as forms ofenvironmentmanagement, enabling village maintenance, allowing demographic growth and furtherexpansion. Apart fromdemographic motivation, the regional limits of the Guarani occupation were probably defined consciously, after an initial expansion impulse and ensuingstability, which must have defined forcedoccupation as a strategy of territorial politics.

Keywords: Guaraní archaeology. Lowlands of South America. Taquari/Antas River Basin. Spatial analysis. Chronology.

SCHNEIDER, Fernanda; WOLF, Sidnei; KREUTZ, Marcos Rogério; GALARCE MACHADO, Neli Teresinha. Tempo e Espaço Guarani: um estudo acerca da ocupação, cronologia e dinâmica de movimentação pré-colonial na Bacia do Rio Taquari/Antas, Rio Grande do Sul, Brasil. Boletim do Museu Paraense Emílio Goeldi. Ciências Humanas, v. 12, n. 1, p. 31-56, jan.-abr. 2017. DOI: http://dx.doi.org/10.1590/ 1981.81222017000100003

Autora para correspondência: Fernanda Schneider. Centro Universitário Univates, Setor de Arqueologia. Rua Avelino Tallini, Bairro Universitário. Lajeado, Rio Grande do Sul, Brasil. CEP 95900-000 (fernandaschneider@universo.univates.br).

Recebido em 10/05/2016

Aprovado em 01/08/2016

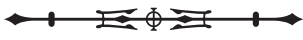




\section{INTRODUÇÃO}

Durante a colonização europeia no leste da América do Sul, observou-se que línguas estreitamente relacionadas eram faladas ao longo de um extenso espaço geográfico. Pertencentes ao tronco linguístico Tupi, eram partilhadas do litoral Atlântico até a Bacia do Rio da Prata, cobrindo uma área de mais de seis mil quilômetros. No sentido Leste-Oeste encontravam-se, não necessariamente de forma constante, do Atlântico até a base dos Andes, ocupando trechos do curso do Amazonas até seus formadores, envolvendo uma distância de quase três mil e quinhentos quilômetros (Brochado, 1989). O tronco Tupi reúne cerca de sessenta línguas, divididas em 10 famílias linguísticas: Awetí, Mawé, Mundurukú, Jurúna, Arikém, Tuparí, Ramaráma, Mondé, Puruborá e Tupí-Guaraní (Rodrigues, 2011). Dessas, as nove primeiras encontram-se distribuídas em uma área relativamente reduzida entre os rios Madeira e o Xingu e o sul do Rio Amazonas, enquanto que, no restante do Brasil, nordeste da Argentina, sul do Paraguai, Uruguai, leste da Bolívia, leste do Peru, Colômbia, Venezuela e Guiana Francesa falam-se línguas muito semelhantes entre si, associadas então à família TupíGuaraní, da qual a língua Tupinambá e a Guaraní fazem parte (La Salvia; Brochado, 1989).

Correspondendo em grande parte aos limites territoriais do contorno linguístico Tupi, mas especialmente Tupí-Guaraní, centenas de sítios arqueológicos com cerâmicas policrômicas aparentadas (pintura em vermelho, preto e branco) foram evidenciados (Brochado, 1984; Noelli, 1999). Com base em observações etnográficas e na linguística histórica, das primeiras décadas da colonização até a década de 1950, viajantes e naturalistas estabeleceram uma forte relação entre essas cerâmicas e os falantes do Tupí-Guaraní. Já na década de 1960, limitando a relação direta entre língua e registro arqueológico, o Programa Nacional de Pesquisas Arqueológicas (PRONAPA), buscou estabelecer características perceptíveis no registro arqueológico, descoladas das informações etnográficas e linguísticas. Dessa forma, os sítios superficiais com cerâmica apresentando pintura policrômica e técnicas plásticas de acabamento (alisado, corrugado, ungulado, escovado) ou superfícies apenas engobadas; assim como sítios com enterramentos secundários em urnas, presença de machados de pedra polida e adornos tembetá, foram associados às populações portadoras de uma 'tradição tecnológica ceramista' nomeada de Tradição Tupiguarani (Chmyz, 1969), sem o uso do hífen, para diferenciar a denominação Tupí-Guaraní, com hífen, referente à família linguística (Scatamacchia, 1990).

Apesar dos esforços do PRONAPA, essa dissociação teórica passou, ao longo dos anos, a dar lugar novamente a uma conexão bastante imediata entre as cerâmicas arqueológicas da Tradição Tupiguarani e os falantes do Tupí-Guaraní (Noelli, 1993). Já durante a década de 1970, como ressalta Corrêa (2014), Meggers e Evans (1973), nomes responsáveis pela execução do PRONAPA, atualizaram suas teorias sobre a origem Tupiguarani com a compilação de dados etnográficos de Martius (1867) e Metráux (1927) e com dados linguísticos de Rodrigues (1964). Foi Brochado (1984), entretanto, quem reformulou a utilização conjugada de Etnografia, Linguística e Arqueologia para o conhecimento do Guarani arqueológico. $\bigcirc$ autor propôs que as cerâmicas consideradas pertencentes à Tradição Tupiguarani fariam parte, na verdade, da Tradição Policroma da Amazônia e, a partir de uma separação espaço-temporal ocasionada pelo aumento demográfico no interior da região amazônica, a Tradição teria se dividido em duas subtradições cerâmicas distintas, a Guarani e a Tupinambá, separadas ainda por línguas diferentes. Assim, os sítios com cerâmica policrômica que se localizassem na porção meridional do território Tupí-Guaraní pertenceriam aos falantes do Guaraní, enquanto que a cultura material evidenciada na porção norte estaria relacionada aos falantes do Tupinambá.

Embora a relação entre língua, dados etnográficos e cultura material tenha se tornado uma forma comum de interpretação na Arqueologia Guarani, ainda hoje não encontra consenso. Em crítica a esse modelo, especialmente com relação à associação direta entre fontes documentais e dados arqueológicos, Soares (2001-2002, 
2012) propôs que fosse desfeito o denominador comum entre o Guarani histórico, etnográfico e arqueológico, sob pena de estar-se criando um "Frankenstein Guarani" que nunca existiu (Soares, 2012). Schiavetto (2003), ao discutir a formação da identidade Guarani na Arqueologia brasileira, entende que a imagem arqueológica dessas populações estaria sendo elaborada a partir da premissa histórico-cultural de que cultura material definiria etnia e esta, por sua vez, a língua. Tais ideias lançariam mão da construção de um Guarani monolítico ou, como argumenta Eremites de Oliveira (2007), favoreceriam a construção de uma etnicidade genérica Guarani, onde parcialidades distintas, sob um ponto de vista êmico, estariam sendo agrupadas equivocadamente em categorias homogêneas. Nessa ótica, com base especialmente nas discussões antropológicas realizadas em 1969 por Barth (1998) e Jones (1997), a autopercepção étnica e formas diversas de organização social Guarani não observáveis no registro arqueológico estariam sendo ignoradas.

Se, por um lado, a discussão referente às parcialidades étnicas e sobre uma identidade homogênea virtual atribuída aos Guarani demonstra-se relevante e latente ao avanço qualitativo da Arqueologia Guarani, por outro, foi na relação entre cultura material, etnia e língua que os principais modelos explicativos para essa disciplina foram estruturados, especialmente referentes a uma longa duração temporal (Meggers; Evans, 1973; Brochado, 1984) e uma tendência à prescritividade cultural (Noelli, 1993). Essas premissas, mas em particular o amplo alcance territorial observado pela dispersão da cultura material associada a essas populações, fez com que desde muito cedo surgissem interesses destinados à compreensão do seu estabelecimento no espaço, mais especificamente sobre a origem desses povos, as rotas de dispersão e a motivação para os deslocamentos. Noelli (1996) ressalta, entretanto, que apesar do volume de trabalhos referentes a temas espaciais, o consenso entre os especialistas apresenta-se apenas na noção da existência de um centro de origem comum do qual os Tupi se distanciaram e se diferenciaram por meio de processos histórico-culturais, uma vez que não há acordo quanto à localização geográfica desse centro e quanto à direção das rotas. Na Arqueologia Guarani, por sua vez, os temas espaciais amplos dividem terreno com preocupações específicas da organização espacial dessas populações, destacando-se debates quanto à distribuição dos sítios na paisagem, à dinâmica da movimentação durante os deslocamentos, e, de forma paralela, discussões cronológicas. Tais temas apresentaram avanços interpretativos importantes a partir da década de 1980 (Brochado, 1984, 1989; Schmitz, 1985, 1991; Schmitz et al., 1990; Scatamacchia, 1990; Ribeiro, 1991, 1995; Noelli, 1993, 1996, 1998a, 1999, 2004; Rogge, 1996, 2004; Dias, 2003; Klamt, 2005; Pestana, 2011; Machado, 2008; Milheira, 2008, 2010; Neves et al., 2011; Wolf, 2012; Kreutz et al., 2014; Milheira; DeBlasis, 2014; Schneider, 2014; Corrêa, 2014; Kreutz, 2015; Bonomo et al., 2015; Almeida; Neves, 2015; De Souza et al., 2016), porém, ainda não se encontram plenamente resolvidos, carecendo de diversas respostas regionais.

Nesse contexto, configurando-se como um estudo regional do processo de ocupação Guarani das várzeas meridionais, este artigo discute a dinâmica espacial e temporal ocorrida nas terras baixas da Bacia do Rio Taquari/Antas, localizada no nordeste do estado do Rio Grande do Sul. Apresentando-se como uma região ainda periférica do ponto de vista do conhecimento Guarani, foi uma das últimas a sofrer contato com as levas colonizadoras europeias no sul do Brasil. Para a discussão pretendida, pensando na contribuição de questões espaciais gerais para a Arqueologia Guarani, mas também específicas para a região da Bacia, três objetivos centrais foram eleitos. $O$ primeiro deles procura traçar os limites da ocupação territorial Guarani na Bacia e o seu estabelecimento na paisagem a partir da distribuição dos sítios evidenciados na região. O segundo propõe discutir a cronologia Guarani na Bacia a partir, então, de dois enfoques: a cronologia regional, por meio de um conjunto de sítios, e a temporalidade intrassítio, a partir do estudo 
cronológico detalhado do sítio RS-T-114, um dos sítios Guarani com o maior número de datas do Rio Grande do Sul. Finalmente, configurando-se como a conjugação dos resultados anteriores, o terceiro objetivo busca interpretar a dinâmica das movimentações Guarani na Bacia. Nesse ponto, destaca-se a reflexão sobre a direção, a velocidade e o ritmo dos deslocamentos ocorridos, objetivando-se compreender, especialmente, se a ocupação das novas áreas era precedida pelo abandono das aldeias antigas, em um movimento conceituado por Brochado (1984) e Noelli (1996) como de "migração", ou se a ocupação ocorria a partir de um comportamento compulsivo e contínuo, com o alastramento de aldeias sem que as antigas sofressem abandono, em um movimento conceituado pelos mesmos autores como de "expansão".

\section{DISTRIBUIÇÃO DOS SÍTIOS NA PAISAGEM, ORGANIZAÇÃO ESPACIAL E CRONOLOGIA: UM BALANÇO GERAL DA ARQUEOLOGIA GUARANI}

Em meio aos temas espaciais discutidos na Arqueologia Guarani, talvez o padrão de distribuição dos sítios na paisagem seja o que apresente as informações mais consensuais. Antes do processo colonizador europeu, a ocupação Guarani abarcou grande parte do leste da América do Sul (Schmitz, 1985, 1991; Scatamacchia, 1990; Rogge, 1996; Noelli, 1996, 1999, 2004), encontrando-se vestígios arqueológicos em mais de 2.900 sítios, distribuídos nos estados brasileiros do Mato Grosso do Sul, de São Paulo, do Paraná, de Santa Catarina e do Rio Grande do Sul; no Paraguai oriental, no nordeste da Argentina e no Uruguai (Noelli, 2004; Bonomo et al., 2015), em um perímetro de terras baixas sul-americanas que circundam os planaltos brasileiros ocupados, por sua vez, por falantes de línguas do Tronco Macro-jê (Brochado, 1989).

Os dados históricos sugerem que no começo do século $X V I$, durante o estabelecimento das primeiras colônias europeias, os Guarani viviam seu auge geográfico e demográfico (Noelli, 2004), com uma população estimada em mais de dois milhões de indivíduos (Melià, 1986). O grande alcance territorial e o sucesso demográfico não passavam apenas pela organização espacial e social, mas também pelo sucesso conquistador diante de outras etnias, apresentando a tendência de incorporar o outro, o não-Guarani, por meio de alianças ou assimilação à custa das contínuas guerras de conquista (Noelli, 1999), encontrando-se sítios Guarani sempre nas camadas superiores dos estratos arqueológicos pré-coloniais (Scatamacchia, 1990). Conforme Noelli (2004), depois dos primeiros contatos com os europeus as populações começaram a declinar, restando, no final do século XVII, poucos grandes núcleos Guarani fora do sistema colonial. Perto de 1700, em grande parte do Rio Grande do Sul, de Santa Catarina, do Paraná, do oeste de São Paulo, do Uruguai e das províncias de Buenos Aires, Entre Ríos, Corrientes e Misiones encontravam-se apenas grupos isolados. Em alguns pontos do centro do Rio Grande do Sul, as datações chegam, entretanto, até finais do século XVIII (Noelli, 2004; Schneider, 2014; Bonomo et al., 2015).

A síntese de Scatamacchia (1990) demonstrou que a maioria dos sítios Guarani se concentra em áreas de clima úmido, sem estação seca e com recursos abundantes, geralmente margeando as terras altas. Fora do núcleo florestal do sistema Paraná-Paraguai-Uruguai, os vestígios são encontrados de forma marginal nas áreas alagadiças do Rio Grande do Sul e Uruguai e na região do Chaco, distribuindo-se em áreas colinares, sobre terraços ou vertentes, sobre cerritos, sobre cordões de conchas, sobre sambaquis, sob abrigos, sobre dunas e em terrenos abrigados perto das praias litorâneas. Apesar da preferência de ocupação por terras baixas, planas ou com leves inclinações (Scatamacchia, 1990; Prous, 1992), assim como por várzeas férteis (Scatamacchia, 1990; Schmitz, 1991; Rogge, 1996; Wolf, 2012; Kreutz et al., 2014), ressalta-se que a distribuição dos sítios também apresentou adaptação a diferentes climas e solos. Enquanto algumas áreas de Floresta Estacional Decidual ao longo de rios maiores localizados no Paraná encontram-se praticamente desprovidas de sítios Guarani (Chmyz, 1981; Parellada, 2005), registros dessas 
populações aparecem em áreas de maiores altitudes da Serra Geral do Paraná (Noelli, 2004) e do Planalto Catarinense (De Souza et al., 2016), assim como em perímetros de transição entre florestas (Wolf, 2012).

As informações coloniais e os dados arqueológicos indicam que a organização espacial configurava-se por um sistema de redes, não se registrando sítios isolados, nem mesmo em áreas periféricas ao território, sendo os isolamentos resultados da queda demográica causada pelo sistema colonial (Noelli, 2004; Bonomo et al., 2015). A partir dos dados etnohistóricos e etnográficos referentes aos Guarani, especialmente vistos em Montoya (1639) e Susnik [1979-1980], faz-se possível ilustrar esse sistema, onde os domínios espaciais refletiriam laços de parentesco e reciprocidade em três níveis territoriais inclusivos: guârá, tekohá e teii (Montoya, 1639; Susnik, [1979-1980]; Noelli, 1993). O guârá representaria uma região delimitada geralmente por rios e subdividida em unidades territoriais socioeconomicamente aliadas, denominados tekohá, representando a aldeia. Sua área era delimitada geralmente por colinas, arroios ou rios, utilizada comunalmente e exclusivamente pelo grupo local. Finalmente, os tekohá eram formados por teî̀ isolados ou agrupados em função das condições locais e políticas. Teîi, 'parcialidade, genealogia', seria a família extensa em linguagem antropológica, podendo ser traduzido também como casa, onde vivia a linhagem e até sessenta famílias nucleares. Segundo relatos dos séculos XVI e XVII, essa organização sociopolítica apresentava estrutura complexa e a localidade era do tipo kindred (Soares, 1997; Noelli, 1999). Apesar do sistema de parentesco, Noelli (1999) observa que nem a 'matrilocalidade' nem a 'patrilocalidade' funcionavam como fatores agregadores, mas sim o prestígio do líder e sua capacidade de organizar grupos guerreiros ou de trabalho, com qualidades de bom orador, guerreiro, agricultor, caçador, articulista político e provedor de grandes festas.

Nesse sistema os tekohá eram organizados a partir da conjugação de três níveis espaciais básicos: a casa, o espaço preservado para caça e pesca e o espaço cultivado
(Angrizani, 2009). A roça, constituída por uma bem estruturada horticultura praticada em clareiras abertas nas florestas por meio da técnica de derrubada e queima da mata (coivara) (Milheira; DeBlasis, 2014), apresentava-se como um importante fator de manutenção do sistema. A grande maioria das plantas cultivadas era de origem tropical, apresentando-se mais de 180 cultivos distribuídos em 36 gêneros diferentes (Noelli, 1993, 1998b), incluindo alimentos como a mandioca (Manihot esculenta Crantz), o amendoim (Arachis hypogea L.), o feijão (Phaseolus vulgaris L.), a batata (Solanum tuberosum L.), o inhame (Dioscorea sp.), a batata-doce (Ipomoea batatas (L.) Lam.), o milho (Zea mays L.) e tipos variados de abóboras (Cucurbita spp.). A alimentação era conjugada ainda com a coleta de plantas silvestres, caça, pesca e cultivo de alguns animais, como larvas e tartarugas (Brochado, 1989).

Assim como a compreensão da distribuição dos sítios na paisagem e aspectos da organização espacial, o quadro temporal Guarani apresenta-se relativamente estabelecido. As primeiras referências cronológicas concisas ocorreram em Brochado (1973), quando este autor apresentou uma popular sequência para a ocupação do leste da América do Sul. A partir de dados gloto-cronológicos e de 54 datas obtidas em Carbono $14\left({ }^{14} \mathrm{C}\right)$, coletadas durante a vigência do PRONAPA, estipulou cinco estágios de ocupação Tupi: período Inicial, entre A.D 0-500; período Antigo, entre A.D 500-900; período Médio, entre A.D 900-1300; período Tardio, entre A.D 1300-1500; período Colonial, entre A.D 1500-1800; e o período Atual, entre A.D 1800-1900.

Partindo dessa sequência, Rogge (1996, 2004) apresentou três estágios de ocupação Guarani para o território que hoje corresponde ao Rio Grande do Sul. Em um estágio inicial, no começo da Era Cristã, a entrada teria ocorrido pelo noroeste e ao longo de várzeas férteis de rios de maior porte, como do Médio Uruguai e Rio Ijuí, alcançando o Alto e o Médio Jacuí. A data em ${ }^{14} \mathrm{C}$ mais antiga do Rio Grande do Sul, Cal. A.D 274, localiza-se, contudo, nas margens do Rio Jacuí, no centro do estado (Bonomo et al., 2015). Em um segundo estágio de expansão, entre os 
séculos VIII e XIII, as populações Guarani teriam ocupado com maior intensidade as áreas férteis da margem esquerda do Rio Jacuí, ao mesmo tempo em que se dirigiam para o Rio Uruguai e se expandiam ao longo da faixa costeira, ocupando também as matas da Serra do Sudeste e alguns locais florestados da Laguna dos Patos. Por fim, em uma terceira onda de ocupação, entre os séculos XIII e XVII, teriam expandido por áreas mais afastadas dos grandes rios e porções mais altas e estreitas dos vales dos rios que descem o Planalto. Assim, estimando que a expansão tenha sido de 0,8 a $1 \mathrm{~km}$ por ano, por volta dos séculos XV e XVI, quando do encontro com colonizadores europeus, os Guarani já ocupariam praticamente todas as áreas florestadas dos vales fluviais e da faixa litorânea.

A partir de uma recente revisão da cronologia Guarani, utilizando então 248 datas obtidas por ${ }^{14} \mathrm{C}$ e Termoluminescência (TL), os resultados de Bonomo et al. (2015) indicaram a região do Alto Rio Paraná como área potencial para as datas mais antigas dessas populações. A partir dessa área inicial, sete principais rotas dispersivas foram observadas, sendo três vias para o norte e quatro vias de dispersão para o sul. Bonomo et al. (2015) interpretaram que os deslocamentos teriam ocorrido em dois períodos de expansão (especialmente sítios novos em áreas novas) intercalados por um período de relativa estabilidade (especialmente sítios novos em áreas já ocupadas). 0 primeiro período significativo de expansão Guarani teria ocorrido entre A.D 0-300, desenvolvendo-se ao longo do Rio Paraná, Rio Ivaí, Bacia do Paranapanema, Rio Uruguai e rios Ibicuí e Jacuí, apresentando uma velocidade de expansão estimada em 750 km² por ano. Os sete séculos seguintes, entre A.D 300-1000, configurariam um período de relativa estabilidade, com a permanência e o aumento de assentamentos em áreas já ocupadas. Em um ritmo lento de expansão estimado em 110 km² por ano, as dispersões para áreas novas teriam sido limitadas, restringindo-se a um avanço para o leste no setor meridional. Esse avanço estaria representado por uma data em TL obtida para o sítio RS-T-114, na Bacia Taquari/Antas, com o resultado de Cal. A.D
570, e pelo sítio Palmeira 2, localizado no Rio dos Sinos, com datação em ${ }^{14} \mathrm{C}$ de Cal. A.D 718. Após esse período de relativa estabilidade, entre A.D 1000-1780 insere-se o maior número de datas analisadas, observando-se um período de notável expansão para novas áreas. Nesse segundo pulso expansionista, além de uma crescente densidade de sítios nas áreas já ocupadas, teria ocorrido forte expansão para todas as direções da Bacia do Prata e Atlântico Sul, em um ritmo de expansão estimado em $500 \mathrm{~km}^{2}$ por ano.

\section{MODELOS DE MOVIMENTAÇÃO ESPACIAL GUARANI}

Apesar da falta de consenso acerca do centro de origem e das rotas de dispersão Guarani, a ideia de que esses povos tiveram sua etnogênese cultural em algum lugar da Amazônia (Metráux, 1927; Rodrigues, 1964; Lathrap, 1970; Meggers; Evans, 1973; Brochado, 1984, 1989; Schmitz, 1985, 1991; Noelli, 1993, 1996, 1998a, 1999; Ribeiro, 1995; Mello; Kneip, 2005; Corrêa, 2014; Almeida; Neves, 2015) é bastante aceita. Assumindo essa origem, dois principais modelos se materializaram na Arqueologia brasileira quanto à dinâmica de movimentação Guarani pelo território, um a partir dos escritos de Meggers (1972, 1975, 1977, 1979) e o outro a partir dos escritos de Lathrap (1970) e Brochado (1984, 1989).

Com proximidade às ideias lançadas em 1838 por Martius (1867) e nos escritos de Julian Steward, organizador do seminal "Handbook of South American Indians", 1946, Meggers (1972) postulou que a cerâmica policrômica teria sido inventada fora da Amazônia, em uma porção geográfica que, hoje, se configura como a Bolívia, e teria sofrido decadência cultural quando levada para o ambiente da Floresta Tropical (Noelli, 1996). No ano seguinte, Meggers e Evans (1973) deslocaram o centro de origem Tupiguarani para a planície amazônica, a leste do Rio Madeira. Além das mudanças degenerativas na cerâmica, Meggers $(1975,1977,1979)$ associou a migração das populações a mudanças climáticas intensas sofridas pela Bacia Amazônica no Holoceno recente, entre 4.000 e 2.000 BP e entre 1.500 
e 400 BP. O clima adverso teria reduzido as áreas florestadas e provocado o processo de dispersão. Nessa teoria, baseada no modelo de refúgios florestais, a Floresta Tropical estaria em processo de retração formando ilhas isoladas, circundada por extensos cerrados. A contínua retração desses refúgios teria chegado a tal ponto que as populações ali estabelecidas, pressionadas pelos fatores naturais limitantes, teriam migrado em busca de novas áreas (Rogge, 1996).

Sobre o legado de Meggers (1972, 1973, 1975, 1977, 1979) pode-se dizer que os traços gerais da teoria dos fatores ambientais limitantes foram utilizados de forma bastante frequente na interpretação da ocupação Guarani do Brasil meridional, como visto em Schmitz (1985), Schmitz et al. (1990), Schmitz (1991), Ribeiro (1991, 1995), Rogge (1996, 2004), Klamt (2005), Pestana (2011), Chmyz et al. (2008) e Machado (2008). Schmitz (1985) e Schmitz et al. (1990) definiram que a movimentação das aldeias Guarani no espaço se daria por motivos econômicos e ecológicos, uma vez que a ocupação de um mesmo local por muitos anos acarretaria na escassez dos recursos naturais. Nesse processo de desocupação, medido com base em seriação do material cerâmico e na distribuição dos sítios do Médio e Alto Jacuí, Schmitz (1985) propôs que as aldeias seriam ocupadas por um período de aproximadamente 30 anos; em movimentos curtos e alternados entre as várzeas, a ocupação do espaço se daria de forma centrípeta, apresentando a movimentação de uma ou talvez duas aldeias em um determinado território de domínio, ocorrendo o deslocamento de todo o grupo de pessoas em direção a um novo local, distando não mais do que 1 km em geral. Nessa mesma linha, as ocupações Guarani no Rio Tibagi, Paraná, foram interpretadas por Chmyz et al. (2008) como cíclicas, apresentando um máximo de oito anos de permanência e posterior migração. Ribeiro (1995) estimou, por sua vez, que nas várzeas mais amplas e férteis do Rio Pardo os Guarani deveriam permanecer por um período relativamente mais extenso, com movimentos migratórios mais demorados, mas em solos menos férteis e suscetíveis de forte erosão, as mudanças de habitação deveriam acontecer com maior rapidez.
Rogge (1996), analisando sítios do Médio Jacuí e do Rio Pardo, postulou que durante a entrada nos ambientes subtropicais do Brasil meridional os Guarani teriam conseguido, por um lado, manter seu ciclo vital paralelo ao padrão amazônico, e, por outro, encontrado limitações que restringiram seu amplo desenvolvimento, tendo sido necessário ajustes locais ao modelo básico. Amparado na noção de fatores ambientais limitantes, interpretou que o processo catalizador do domínio territorial Guarani na região seriam as várzeas, uma vez que as estratégias de controle sobre essas áreas, que, apesar de férteis, eram restritas em altitudes maiores, teriam impulsionado uma intensa movimentação territorial. Dois outros fatores foram acionados pelo autor como catalizadores da movimentação das aldeias. Um deles refere-se ao tempo relativamente curto das roças, não necessariamente sobre o esgotamento dos solos, mas relacionado às dificuldades de manejo agroflorestal pós-derrubada da mata para o plantio, que exigiriam um tempo de pousio. $\bigcirc$ outro argumento refere-se à impossibilidade de permanência duradoura nas aldeias por conta da não retirada do lixo das casas. Esse mesmo argumento apresenta-se em Schmitz et al. (1990) nas pesquisas desenvolvidas no sítio Candelária I, no Rio Pardo, quando as Camadas de Solo Antropogênico com abundantes vestígios orgânicos, cerâmicos e líticos foram interpretadas necessariamente como estruturas de habitação com acúmulo de lixo doméstico. Posteriormente, Rogge (2004) incluiu no debate assertivas relacionadas às pressões interétnicas e fenômenos de fronteiras para a compreensão dos fatores da propulsão Guarani para novos territórios.

O legado iniciado a partir dos escritos de Meggers $(1972,1973,1975,1977,1979)$ para a construção acadêmica da espacialidade Guarani partiu de uma lógica relacionada à limitação ambiental, quando os deslocamentos foram previstos como migrações populacionais e as movimentações regionais pontuadas geralmente como de alta rotatividade de aldeias, seja em relação ao abandono de uma aldeia e o estabelecimento de uma nova ou em razão do retorno para as antigas. Diferente disso, Lathrap (1970), 
sob a influência de nomes como Schmidt, Nordenskiöld e Sauer, assim como resumido por Neves (2007), da linguística de Rodrigues (1964), e de forma velada, nos escritos de Metráux (1927), como sugere (Noelli, 1996), propôs que o padrão de ocupação Tupi ao longo do espaço teria se apresentado de forma radial, ou seja, como uma expansão compulsiva, lenta e gradual pelo território a partir de um ponto central, supondo-se então tratar-se da Amazônia Central (crítica com relação à área de origem em Neves (2007)). Nessa ideia, conhecida como hipótese cardíaca, a dispersão poderia ter sido o resultado de um processo de crescimento da população e colonização agrícola das várzeas férteis da Bacia Amazônica, o que teria levado, em seguida, à ocupação de outras planícies aluviais e não aluviais da América do Sul.

Essas ideias influenciaram fortemente o trabalho de Brochado (1984, 1989). Para compor a popular teoria do 'enxameamento', o autor incluiu as assertivas do modelo cardíaco, abrindo precedentes para se pensar que os movimentos Tupi não foram exatamente migrações, no sentido de que as regiões de onde saíram não ficavam vazias, pelo contrário, a população continuava crescendo até o ponto da inevitável saída de novas vagas humanas. Nessa dinâmica compulsória chamada de 'enxameamento', o sistema de adjudicação e a vida cerimonial dos grupos locais Tupi só seriam efetivos para manter a coesão até certo tamanho da população, o que impulsionava a formação de novos grupos. Os deslocamentos foram conceituados como expansões, sugerindo-se que essas teriam se desenrolado em dois momentos: em um primeiro, ao longo dos principais cursos fluviais; e em um segundo, com o aumento da pressão demográfica, com a ocupação dos afluentes menores. Essas colonizações teriam, no caso Guarani, percorrido os cursos dos rios Paraná, Paraguai e Uruguai em um sentido Norte-Sul.

As ideias de Lathrap (1970) e o 'enxameamento' de Brochado $(1984$, 1989) acabaram por formar um consistente eixo de interpretação do comportamento espacial Guarani. Entre os autores que seguiram essa linha de pensamento,
Noelli (1993, 1998b) apresentou notável convergência de ideias, ampliando, ainda, a noção ecológica para a ocupação dos espaços Guarani. Influenciado pelos autores citados e por trabalhos de Etnobiologia, sugeriu que os Guarani teriam exercido grande influência na paisagem quando, a partir da criação de espaços verdes antrópicos, como áreas florestais adequadas às necessidades cotidianas de construção, alimentação e manutenção simbólica da aldeia, teriam diminuído o risco de esgotamento de recursos naturais e rompido com o condicionante ambiental limitante. Da mesma forma, a partir de sistemáticos manejos agroflorestais e da inserção de espécies antrópicas na paisagem, incluindo o intercâmbio de plantas a longas distâncias, teriam modificado a vegetação dos locais ocupados e transformado socialmente o ambiente em um espaço verde compatível com o padrão socioeconômico desejado.

O estudo de Bonomo et al. (2015) apontou algumas divergências com relação às rotas dispersivas e à cronologia estabelecida por Brochado (1984), porém, muitas outras questões apresentaram convergência. Apesar de as datas disponíveis indicarem até o momento que o Alto Paraná foi a área com as primeiras ocupações Guarani, Bonomo et al. (2015) ressaltam que as numerosas informações etnohistóricas e a presença de vasilhas Guarani em coleções paraguaias, somadas à falta de sítios arqueológicos Guarani datados no Paraguai e em outros locais do Brasil, como Rondônia e Mato Grosso do Sul, não permitem que a dispersão Norte-Sul estipulada por Brochado seja descartada. A cronologia obtida confirma, por outro lado, a hipótese de Brochado de que a entrada das populações Guarani teria começado a partir do leste do Rio Paraguai. Da mesma forma, os dados de deslocamentos gerados em Bonomo et al. (2015) inclinaram-se para o modelo de expansão de 'enxameamento' e para as ideias ecológicas de Noelli (1993, 1998b). Os resultados apresentados demonstraram que aldeias isoladas foram inexistentes, sugerindo que para cada data antiga ocorreriam datas posteriores. Nesse sentido, os deslocamentos indicariam um processo de 
expansão populacional e não de migração, demonstrando que uma vez que os primeiros assentamentos Guarani foram estabelecidos em diferentes áreas da Bacia do Prata houve continuidade de ocupação nesses lugares, com manutenção dos territórios anteriormente povoados, e, em alguns casos, até mesmo por centenas de anos.

\section{OS GUARANI NA BACIA DO RIO TAQUARI/ ANTAS: ÁREA DE ESTUDO, CONTEXTO FITOGEOGRÁFICO E METODOLOGIA}

A Bacia do Taquari/Antas apresenta como principal recurso hídrico o Rio Taquari, com suas nascentes no extremo leste do Planalto dos Campos Gerais. Das nascentes até a confluência com o Rio Carreiro ainda recebe o nome de Rio das Antas, passando a partir daí a denominar-se Taquari, desembocando então no Rio Jacuí, do qual é o maior afluente. Seus principais afluentes à margem esquerda são os rios Camisas, Tainhas, Lajeado Grande e São Marcos, e pela margem direita, os rios Quebra-Dentes, da Prata,
Carreiro, Guaporé, Forqueta e Taquari-Mirim. Limita-se ao norte pela Bacia do Rio Pelotas, a oeste e ao sul pelas Bacias do Rio Pardo e do Rio Jacuí, e a leste pelas Bacias dos rios Caí e Sinos (Fepam, 2016). Ao longo dos 26.428 $\mathrm{km}^{2}$ que compõem a Bacia, este estudo limita-se a explorar o território em que evidências das populações Guarani aparecem, configurando-se em um perímetro de 10.604 km² na porção centro-sul da Bacia (Figura 1).

Ao longo desse perímetro, a geomorfologia geral insere-se no Domínio Morfoestrutural das Bacias e Coberturas Sedimentares, no qual são observadas duas regiões geomorfológicas distintas, a Depressão Central Gaúcha e o Planalto das Araucárias. O Planalto das Araucárias possui características heterogêneas, variando entre formas de relevo amplas e aplanadas até o nível mais profundo de entalhamento. Por sua vez, a Depressão Central Gaúcha, observada no extremo sul dessa porção, apresenta relevo homogêneo, sem muitas variações altimétricas, onde prevalecem formas conhecidas como coxilhas e vastas

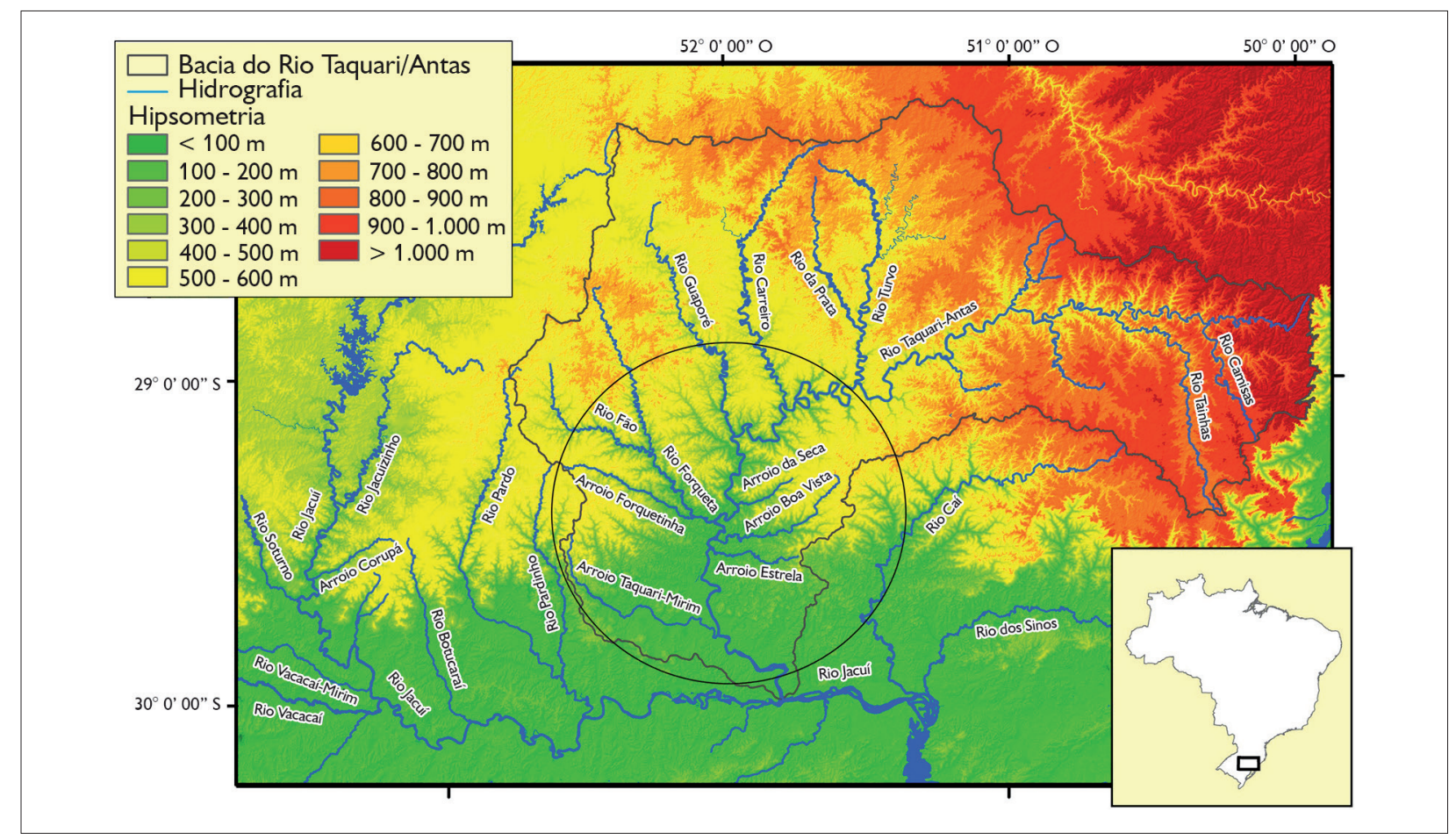

Figura 1. Delimitação da porção centro-sul da Bacia do Taquari/Antas.

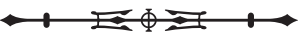


superfícies planas, rampeadas e recobertas por colúvios (Justus et al., 1986). Em termos fitoecológicos, a porção centro-sul da Bacia insere-se no bioma Mata Atlântica. Ao norte, acompanhando o relevo de maior altitude do Planalto das Araucárias, apresenta a formação de Floresta Ombrófila Mista, com a marcante presença de Araucaria angustifolia (Bertol.) O. Kuntze, e ao sul e ao centro, acompanhando a altitude mais branda a partir da fronteira do Planalto das Araucárias e da Depressão Central Gaúcha, apresenta formação de Floresta Estacional Semidecidual e Decidual (Teixeira et al., 1986).

Para a compreensão dos limites da ocupação Guarani e sua paisagem de estabelecimento nessa região realizou-se o levantamento dos sítios Guarani registrados na Bacia a partir de bibliografias (Werlang, 1981; Goldmeier, 1983; Ribeiro et al. 1989; Klamt et al., 1998; Machado, 2003, 2008; Kreutz, 2008; Fiegenbaum, 2009; Rosa, 2009; Vicroski; Trommer Thaddeu, 2010; Motta, 2011; Wolf, 2012; Kreutz, 2015) e de dados do Cadastro Nacional de Sítios Arqueológicos do Instituto do Patrimônio Histórico e Artístico Nacional (CNSA/PHAN, c2014). Foram verificados 121 sítios arqueológicos na Bacia, dos quais 108 apresentaram coordenadas geográficas. Os sítios com coordenadas geográficas foram inseridos em um mapa hipsométrico, delimitando-se, assim, o perímetro de ocupação Guarani para a Bacia do Taquari/Antas e sua inserção na paisagem.

O segundo ponto de discussão refere-se ao estabelecimento de parâmetros cronológicos para a área de ocupação Guarani na Bacia em dois aspectos: o contexto regional e o contexto intrassítio. Para a obtenção da cronologia regional foram utilizadas 12 datações em ${ }^{14} \mathrm{C}$, provenientes de cinco sítios arqueológicos estabelecidos em áreas estratégicas do perímetro Guarani observado na Bacia. A delimitação das áreas estratégicas partiu de uma divisão hipotética do perímetro em área 'meridional', 'central' e 'setentrional', a fim de se compreender o padrão cronológico relacionado com a posição geográfica dos sítios. No sul do perímetro Guarani na Bacia encontra-se datado o sítio RST-117 (uma data); na região central encontram-se datados os sítios RS-T-101 (uma data) e o RS-T-114 (oito datas), ambos margeados pelo Rio Forqueta; e inseridos na região setentrional encontram-se datados os sítios RS-03 (uma data) e o sítio Favaretto Escavação (uma data). Com relação à data do sítio Favaretto Escavação, ressalta-se que não foi possível acessar o resultado RCYBP (1-Sigma) disponibilizado no laudo da data, estando limitada a análise dessa data apenas ao resultado calibrado parcial publicado em Machado (2008).

Por sua vez, a discussão da cronologia intrassítio deu-se a partir da elaboração de uma documentação cronológica sistemática e concisa do sítio RS-T-114, localizado na margem direita do Rio Forqueta. Nesse sítio, selecionado como estudo de caso por apresentar uma preservação sui generis no contexto da área de estudo, assim como um interessante histórico de pesquisas arqueológicas, realizaram-se oito datas em ${ }^{14} \mathrm{C}$, das quais quatro foram obtidas de forma sequencial em uma camada única de ocupação Guarani denominada aqui como 'Camada de Solo Antropogênico', apresentando-se composta por terra escura, vestígios cerâmicos, líticos, arqueofauna, sementes e carvões. A análise da Camada de Solo Antropogênico, assim como da cultura material nela evidenciada, demonstrou tratar-se de uma estrutura arquitetônica (Noelli, 1993; Soares, 2004) com presença de áreas de combustão internas (Schneider, 2014). A coleta sistemática de carvões deu-se no sentido vertical, escolhendo-se um local entre o perímetro de maior preservação e o de maior incidência de carvões. Esses dois fatores coincidiram em um ponto em que a Camada apresentou 0,08 m de espessura. Para que fosse atingida de forma integral, a fim de se obter dados como o reconhecimento do histórico temporal da ocupação (período inicial, médio e final) e o ritmo de permanência nesse sítio (contínuo ou intermitente), realizaram-se coletas de amostras a cada 0,02 m de profundidade, obtendo-se, então, quatro pontos sistemáticos de datação (Figura 2). Por fim, para a discussão dos movimentos regionais ocorridos durante a ocupação territorial, especialmente referente às possíveis direções, velocidade de ocupação e ritmo dos movimentos regionais, traçou-se um paralelo interpretativo entre o mapa 


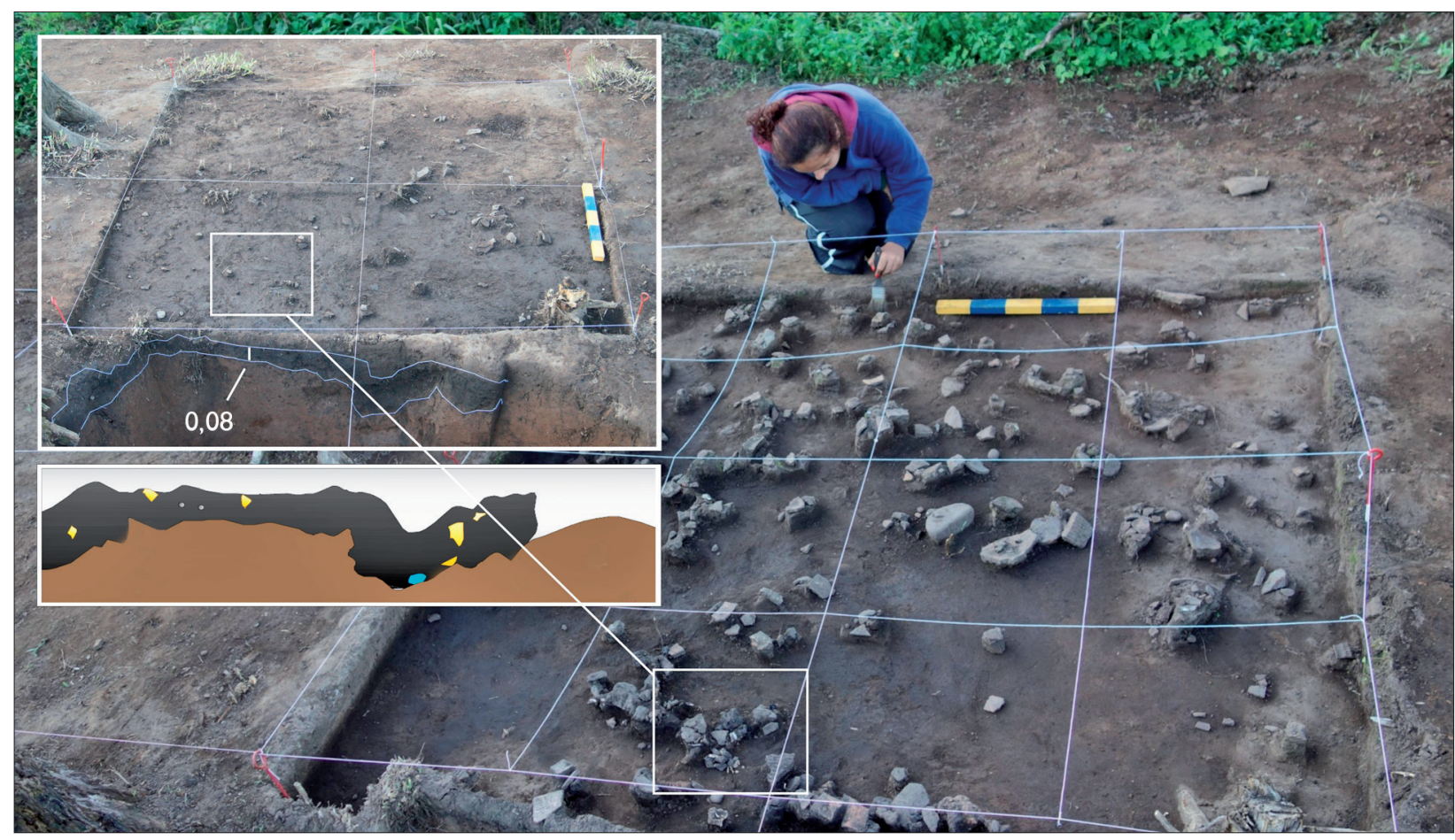

Figura 2. Perímetro de coleta de carvões para datação sistemática em ${ }^{14} \mathrm{C}$ na Camada de Solo Antropogênico do sítio RS-T-114. Fotos: Schneider, 2014.

de distribuição dos sítios Guarani na Bacia e os resultados cronológicos obtidos para o âmbito regional e intrassítio.

\section{RESULTADOS E DISCUSSÃO}

\section{DISTRIBUIÇÃO ESPACIAL DOS SÍTIOS ARQUEOLÓGICOS GUARANI NO CONTEXTO DA BACIA}

Em finais da década de 1960, mapeamentos arqueológicos coordenados por Pedro I. Schmitz demonstraram os primeiros indícios da ocupação Guarani na Bacia do Taquari/ Antas, apontando a distribuição dessas populações na porção sul do Planalto das Araucárias. No mesmo período, os arqueólogos Pedro A. Mentz Ribeiro e Guilherme Naue registraram sítios Guarani na porção norte da Depressão Central Gaúcha. A partir do final da década de 1990, mapeamentos arqueológicos sistemáticos voltados algumas vezes para a realização de laudos de execução de obras de engenharia, e, em outras, de caráter estritamente acadêmico, atestaram a projeção lançada na década de 1960 de que as planícies da Bacia possuíam um interessante panorama arqueológico a ser explorado (Kreutz et al., 2014).

Os 121 sítios evidenciados nesse perímetro indicaram que a concentração de ocupação Guarani ocorreu na área centro-sul da Bacia (Apêndice). Desses sítios, 59 localizam-se entre os municípios de Veranópolis, Cotiporã, Bento Gonçalves, Guaporé e Muçum, na porção norte do perímetro Guarani, em uma zona geográfica do Planalto das Araucárias em que o vale torna-se mais encaixado, assumindo a forma de $\mathrm{V}$. Na região central do perímetro, em uma área em que o Planalto das Araucárias limita-se à Depressão Central Gaúcha, proporcionando o aparecimento de planícies mais extensas em um dos lados dos rios, áreas de menor altitude e fronteiras florestais, foram identificados 27 sítios inseridos nos municípios de Marques de Souza, Travesseiro, Forquetinha, Arroio do

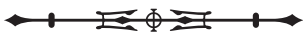


Meio, Colinas, Teutônia, Lajeado e Estrela. Na porção sul do perímetro, já na Depressão Central Gaúcha, onde as planícies apresentam-se mais extensas, foram evidenciados 35 sítios entre os municípios de Cruzeiro do Sul, Tabaí, Taquari, Montenegro, Fazenda Vilanova e Venâncio Aires.

De forma geral, os sítios encontram-se próximos a rios e arroios e geralmente em áreas inferiores a 100 metros de altitude, não se observando sítios acima de 400 metros de altitude na região (Figura 3). A ocupação Guarani evidenciada na Bacia não ocorreu isolada do processo de expansão dessas populações pelas várzeas meridionais. Ao sul e oeste do perímetro Guarani da Bacia localizam-se planícies extensas de áreas margeadas pelos rios Jacuí e Pardo, e, a leste, planícies dos rios Caí e Sinos. Essas áreas apresentaram a incidência bastante frequente de sítios Guarani (Ribeiro, 1991; Rogge, 1996; Dias, 2003), configurando o que parece ser uma faixa de ocupação que partiu do oeste em direção ao leste do estado (Rogge, 1996). Evidenciam-se sítios mais ao sul desses rios (Bonomo et al., 2015), entretanto, de uma forma que o avanço Guarani parece ter diminuído nesse sentido.
Os limites norte, noroeste e nordeste do perímetro de ocupação Guarani na Bacia parecem evidenciar, por sua vez, uma dinâmica diferente. Nessa porção os sítios apresentam-se limitados às paisagens altas em que sítios Proto-Jê tornam-se muito frequentes. Em relação a esses povos, encontram-se sítios no noroeste da Bacia, entre os rios Fão, Forqueta e Guaporé, em altitudes que variam de 400 a 700 metros (Wolf, 2012), não se registrando, nessas áreas, sítios multicomponenciais ou traços de contanto interétnico entre Guarani e Proto-Jê. Acompanhando o Rio Taquari/Antas na direção nordeste que este segue, os sítios Proto-Jê mais próximos da área Guarani encontram-se nos municípios de Flores da Cunha e Caxias do Sul (Corteletti, 2008; Machado, 2008). Fora da Bacia do Taquari/Antas, nas áreas de maiores altitudes da Bacia do Rio Caí, Corteletti (2008) destacou a ocorrência de três sítios Guarani em áreas consideradas pouco comuns para o estabelecimento dessas populações, especialmente pelo padrão hipsométrico. Tais sítios sugerem um discreto avanço Guarani para as terras altas, porém, diferente da dinâmica evidenciada no

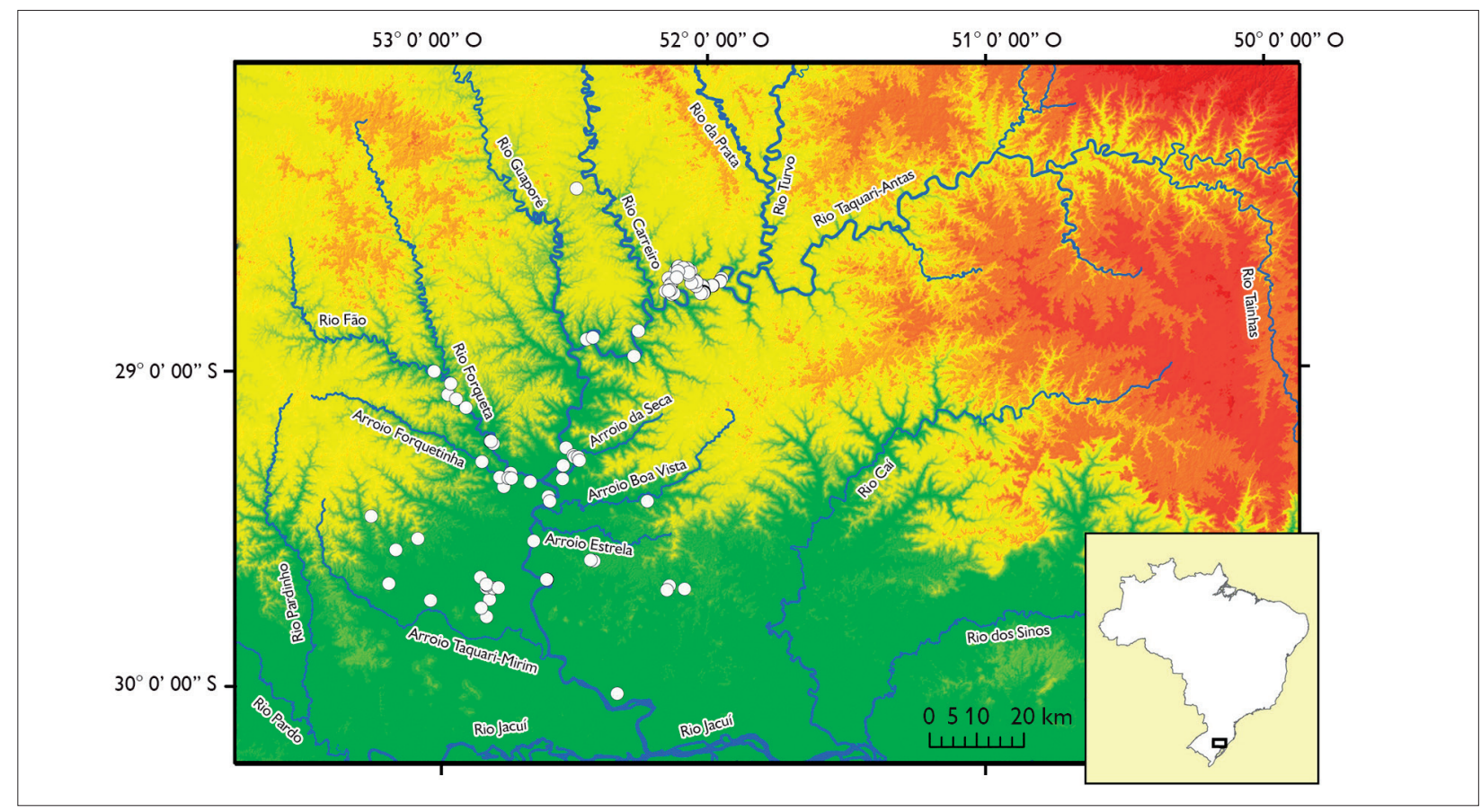

Figura 3. Distribuição dos sítios Guarani na paisagem hipsométrica da Bacia do Taquari/Antas.

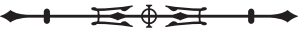


Planalto Catarinense em relação ao avanço desses povos sobre os territórios Proto-Jê, quando a monumentalização da paisagem Jê parece denunciar uma forma de repelir o avanço Guarani (De Souza et al., 2016), o progresso dessas populações para zonas culturais limítrofes da Bacia do Taquari/Antas não se encontram próximas da resolução.

\section{A DINÂMICA CRONOLÓGICA DA OCUPAÇÃO GUARANI NA BACIA}

Para a compreensão do papel da Bacia do Taquari/Antas no processo de ocupação Guarani fez-se necessário o estabelecimento cronológico do perímetro de ocupação traçado para a região. As datas em ${ }^{14} \mathrm{C}$ calibradas, representando 95\% de probabilidade, demonstraram um período de ocupação possível entre o início do século XIV e o final do século XVIII (Tabela 1).

Esses resultados inserem a entrada Guarani na última onda de ocupação apresentada por Rogge (1996), quando as áreas próximas ao Planalto começaram a ser ocupadas. Os resultados coincidem ainda com o último período de expansão estipulado por Bonomo etal. (2015), quando, para esses autores, após um período de relativa estabilidade de 700 anos, entre A.D 1000-1780 teria ocorrido um segundo momento de expansão Guarani, notando-se uma crescente densidade de sítios nas áreas já ocupadas e forte ampliação para direções novas. Apesar disso, no quadro cronológico estabelecido por Bonomo et al. (2015), ao basearem-se no resultado de 10 datas do sítio RS-T-114 obtidas pelo método de TL (Kreutz, 2008; Kreutz et al., 2014), o início da ocupação Guarani na Bacia do Taquari/Antas aparece já no século VI, em um período anterior ao proposto para o presente artigo. Apesar de Bonomo et al. (2015) relatarem pouca variação entre os métodos de ${ }^{14} \mathrm{C}$ e TL nos contextos revisitados, para o sítio RS-T-114, de forma específica, a realização posterior de datas pelo método de ${ }^{14} \mathrm{C}$ não confirmou a cronologia estabelecida por TL (Fiegenbaum, 2009; Wolf, 2012; Schneider, 2014). Os resultados em TL apresentaram uma variação de nove séculos de ocupação, conferindo um período de ocupação entre os séculos VI e XIV, com um possível abandono do sítio antes mesmo da chegada dos europeus na região. Das oito datas em ${ }^{14} \mathrm{C}$ obtidas para esse sítio, duas foram realizadas no mesmo contexto das datas em $\mathrm{TL}$, fornecendo o resultado de 560 $\pm 40 \mathrm{BP}$ e $300 \pm 30 \mathrm{BP}$, esse último consideravelmente posterior (Schneider, 2014); da mesma forma, em nenhum outro contexto da Bacia datas anteriores ao século XIV foram obtidas para sítios Guarani (Machado, 2008; Wolf, 2012; Kreutz, 2015) ou indicaram a desocupação dos sítios antes

Tabela 1. Datas em ${ }^{14} \mathrm{C}$ apresentadas para os sítios Guarani da Bacia do Taquari/Antas.

\begin{tabular}{c|c|c|c}
\hline Sítio & RCYBP (1-Sigma) & Cal. A.D (2-Sigma) & Referência \\
\hline RS-T-114 & $240 \pm 30$ (Beta 367375) & $1640-1806$ & Dos autores (2017) \\
\hline RS-T-114 & $260 \pm 30$ (Beta 388514) & $1665-1800$ & Schneider (2014) \\
\hline RS-T-114 & $300 \pm 30($ Beta 303993) & $1490-1660$ & Schneider (2012) \\
\hline RS-T-114 & $350 \pm 30($ Beta 388513) & $1485-1650$ & Wolf (2012) \\
\hline RS-T-101 & $370 \pm 30($ Beta 326926) & $1450-1630$ & Kreutz (2015) \\
\hline RS-T-117 & $360 \pm 30($ Beta 422489) & $1465-1645$ & Kreutz (2015) \\
\hline RS-03 & $390 \pm 30($ Beta 422490) & $1455-1630$ & Schneider (2014) \\
\hline RS-T-114 & $410 \pm 30($ Beta 388512) & $1515-1625$ & Wolf (2012) \\
\hline RS-T-114 & $410 \pm 30($ Beta 326927) & $1440-1620$ & Machado (2008) \\
\hline Favaretto Escavação & $\ldots . . \quad$ Beta 205841) & $1420-1460$ & Schneider (2014) \\
\hline RS-T-114 & $490 \pm 30$ (Beta 388515) & $1300-1430$ & Fiegenbaum (2009)
\end{tabular}

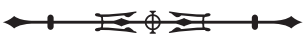


do século XVII (Schneider, 2014). As questões relacionadas à discrepância de resultados entre os métodos exigiram que se escolhesse, por ora, apenas um método de datação, estabelecendo-se então a escolha pelo ${ }^{14} \mathrm{C}$.

As datas calibradas permitiram interpretar que 0 período mais ativo de estabelecimento dos assentamentos na Bacia deu-se até finais do século XVII. Das 12 datas obtidas, sete datas de quatro sítios distintos (RS-03, RS-T-114, RS-T-101 e RS-T-117) apresentam esse intervalo final em seu quadro temporal. Embora a data mais recente apresentada para o quadro cronológico, Cal. A.D 1665-1800, possa inserir a Bacia em meio ao período mais tardio de desapropriação Guarani visto no centro do Rio Grande do Sul, isto é, durante o século XVIII (Noelli, 2004; Bonomo et al., 2015), o abandono da maioria das aldeias Guarani na região parece ter ocorrido durante o século XVII. Coincidindo com esse momento, entre as décadas de 1630 e 1640 se apresenta uma tentativa de inserção de redução jesuítica na região, assim como processos de bandeiras paulistas
(Relly et al., 2008; Kreutz, 2015), eventos-chave para a desestruturação das aldeias Guarani em grande parte dos espaços meridionais do continente americano (Noelli, 2004). Independente do século exato de desapropriação dos assentamentos, o período geral de ocupação Guarani na Bacia parece corresponder a um amplo espaço de tempo que pode chegar a até cinco séculos. Além disso, a convergência entre os períodos de ocupação para os sítios Guarani (Figura 4), acrescido da data Cal. A.D 1470 publicada para o sítio Favaretto Escavação (Machado, 2008), parece demonstrar que a ocupação Guarani deu-se de maneira contemporânea na Bacia do Taquari/Antas, em uma relação contínua de ocupação regional.

Além da discussão de uma continuidade regional de ocupação, o exercício de obtenção de datas sistemáticas no sítio RS-T-114 proporcionou reflexões referentes ao tempo de permanência da ocupação nas aldeias. Os resultados calibrados para esse sítio apresentaram um período de ocupação entre Cal. A.D 1420-1460 e Cal.

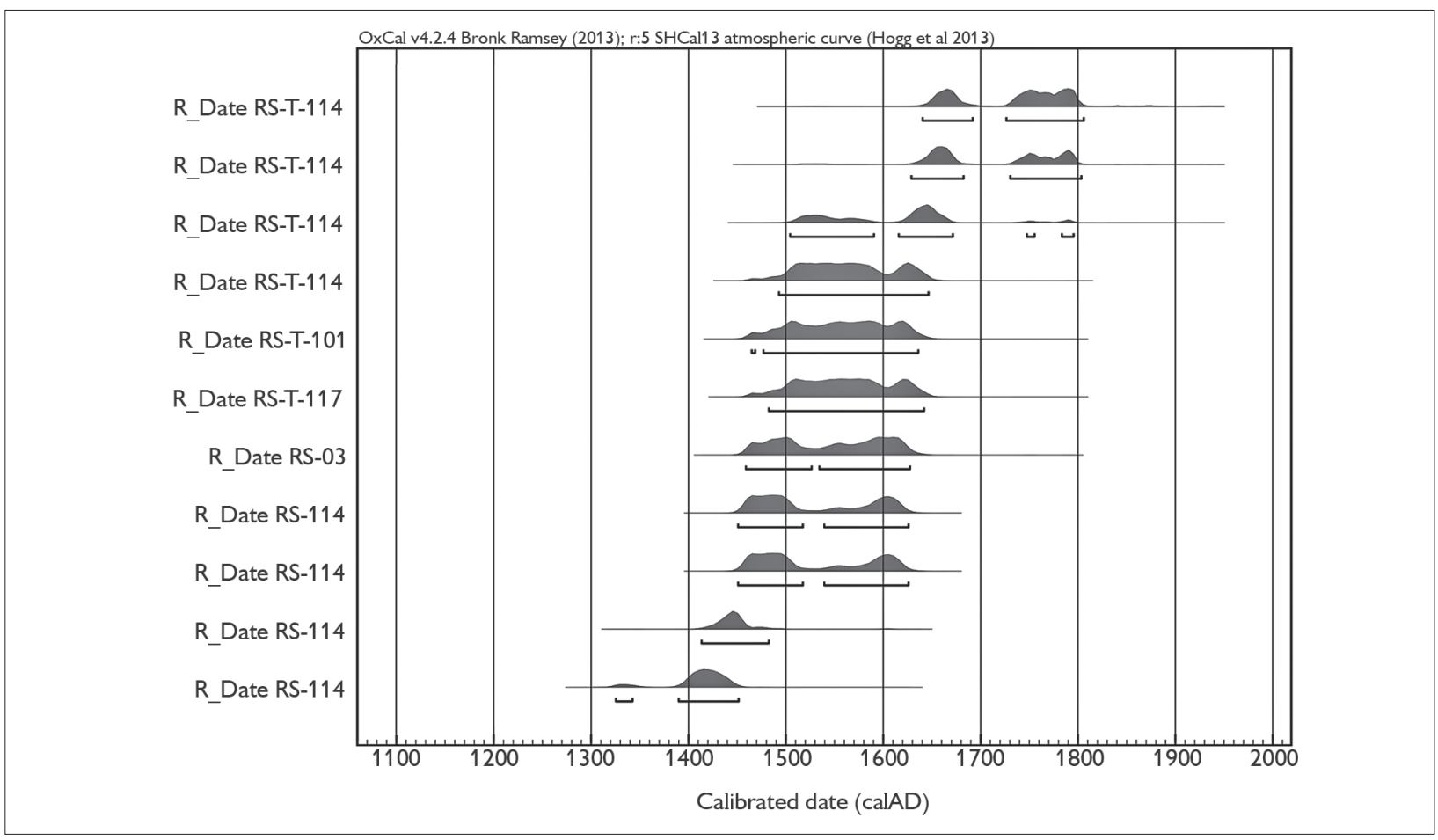

Figura 4. Datas em ${ }^{14} \mathrm{C}$ apresentadas para os sítios Guarani da Bacia do Taquari/Antas.

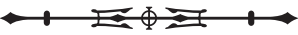


A.D 1665-1800, correspondendo à possibilidade de uma ocupação de mais de três séculos em um mesmo contexto arqueológico (Tabela 2).

Entre os resultados obtidos observou-se a inversão estratigráfica entre as amostras da primeira e da terceira camadas, cujo intervalo mais recente está localizado na terceira camada e o terceiro mais antigo está localizado na primeira camada. Apesar disso, o perfil da Camada de Solo Antropogênico não apresentou nenhum indício de ruptura estratigráfica, estando a inversão relacionada, muito provavelmente, com ação leve de uproontig, onde há elevação das raízes de plantas ao cair, ou por 'faunaturbação', ocasionada pelo revolvimento da terra por animais (Milder, 2000). Levando em conta a falta de uma ruptura estratigráfica que pudesse sugerir, por exemplo, um evento de abandono e posterior reocupação da área, foi possível perceber, a partir da correção da sequência estratigráfica (Figura 5), que a ocupação não ocorreu somente de forma longa no sítio RS-T-114, mas também contínua, tratando-se de uma aldeia que foi mantida em atividade por séculos consecutivos.

\section{DIREÇÃO, VELOCIDADE E RITMO DA MOVIMENTAÇÃO GUARANI NA BACIA}

Rogge (2004), seguindo a ideia de que os rios de maior porte foram ocupados primeiro (Brochado, 1984, 1989), entende que em uma direção geral de oeste para leste, partindo do Baixo Rio Paraná, os Guarani deveriam ter
Tabela 2. Datas em ${ }^{14} \mathrm{C}$ apresentadas para a Camada de Solo Antropogênico do sítio RS-T-114.

\begin{tabular}{c|c|c|c}
\hline Camada & $\begin{array}{c}\text { RCYBP } \\
(1 \text {-Sigma })\end{array}$ & $\begin{array}{c}\text { Cal. A.D } \\
\text { (2-Sigma) }\end{array}$ & Referência \\
\hline $1(0,02 \mathrm{~m})$ & $\begin{array}{c}410 \pm 30 \\
(\text { Beta } 388512)\end{array}$ & $1515-1625$ & $\begin{array}{c}\text { Schneider } \\
(2014)\end{array}$ \\
\hline $2(0,04 \mathrm{~m})$ & $\begin{array}{c}350 \pm 30 \\
(\text { Beta 388513) }\end{array}$ & $1485-1650$ & $\begin{array}{c}\text { Schneider } \\
(2014)\end{array}$ \\
\hline $3(0,06 \mathrm{~m})$ & $\begin{array}{c}260 \pm 30 \\
(\text { Beta } 388514)\end{array}$ & $1665-1800$ & $\begin{array}{c}\text { Schneider } \\
(2014)\end{array}$ \\
\hline $4(0,08 \mathrm{~m})$ & $\begin{array}{c}490 \pm 30 \\
(\text { Beta 388515) }\end{array}$ & $1420-1460$ & $\begin{array}{c}\text { Schneider } \\
(2014)\end{array}$ \\
\hline
\end{tabular}

cruzado o Rio Grande do Sul pelo eixo formado pelos rios Uruguai, Ijuí e Jacuí. Nessa mesma linha, Fiegenbaum (2009), Kreutz et al. (2014) e Kreutz (2015) sugerem que, a partir da conexão com o Rio Jacuí os Guarani teriam se fixado nas planícies do Rio Taquari/Antas, e, ao seguirem em uma direção sul-norte, teriam ocupado os maiores afluentes desse rio, como o Forqueta, e recursos hídricos de menor porte, como os arroios. Embora tal dinâmica pareça provável para o contexto da Bacia, o quadro de datas estabelecido não permite, até o momento, a confirmação de uma direção sul-norte para os deslocamentos Guarani na região. O cruzamento entre as datas e a localização dos sítios demonstrou que as mais antigas situam-se, respectivamente, no sítio RS-T-114, em uma região intermediária do perímetro de ocupação, e

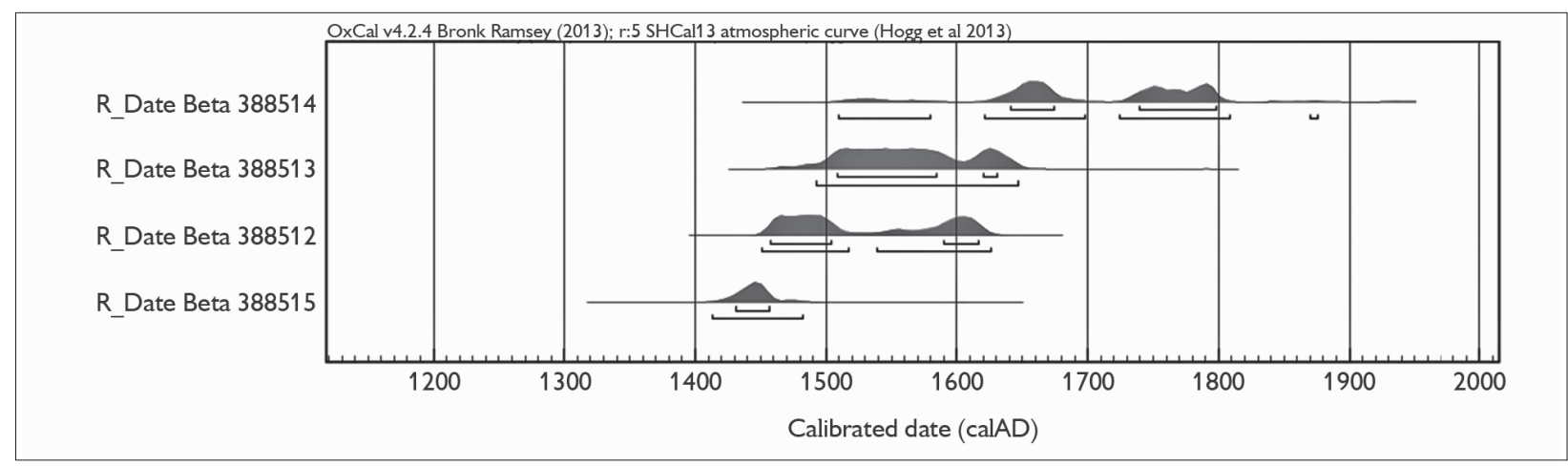

Figura 5. Sequência estratigráfica corrigida para as datas em ${ }^{14} \mathrm{C}$ obtidas para a Camada de Solo Antropogênico do sítio RS-T-114.

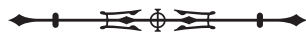


no sítio Favaretto Escavação, na região setentrional do perímetro de ocupação. A data mais ao sul (RS-T-117), por sua vez, situa-se em um intervalo posterior, entre o século XV e XVII. Apesar disso, muito provavelmente o estabelecimento desse quadro deu-se pela falta de uma cronologia sistemática na grande maioria dos sítios datados, ocasionando, dessa forma, uma antiguidade provisória à região central e norte do perímetro de ocupação.

A presença de datas convergentes entre os sítios RS-T-117 (360 \pm 30 BP), RS-T-101 (370 \pm 30 BP), RS03 (390 \pm 30 BP) e RS-T-114 (410 \pm 30 BP) indica que, durante o século XVI, desde o sul até o norte, o perímetro Guarani estaria ocupado de forma integral (Figura 6). Partindo do pressuposto de que a direção dos deslocamentos tenha sido sul-norte, entretanto, é possível recuar ainda mais o período de dominação dos limites territoriais na Bacia. A data estabelecida para o sítio Favaretto Escavação, isto é, na área setentrional do perímetro, permite pensar que, já no século XV, cerca de uma centena de anos depois da entrada dos Guarani na região, as áreas limites do perímetro de ocupação, cerca de 120 quilômetros em linha reta, estariam definidas. Com relação à velocidade de ocupação da Bacia, estima-se, mesmo que de forma hipotética, um deslocamento de $106 \mathrm{~km}^{2}$ por ano, indicando, quando comparado aos resultados apresentados por Bonomo et al. (2015), uma ocorrência lenta. Apesar disso, levando-se em conta que o quadro de datas na área setentrional da Bacia apresenta-se limitado a duas datas e que o padrão de deslocamento apresentado por Bonomo et al. (2015) para assentamentos estabelecidos depois do A.D 1000 indica um ritmo rápido, acredita-se que a ocupação do perímetro Guarani na Bacia possa ter ocorrido de maneira ainda mais veloz.

Além de pistas sobre a velocidade de ocupação, a convergência de datas entre os sítios sugere que as movimentações na Bacia tenham assumido um ritmo de expansão, assim como projetado por Lathrap (1970),

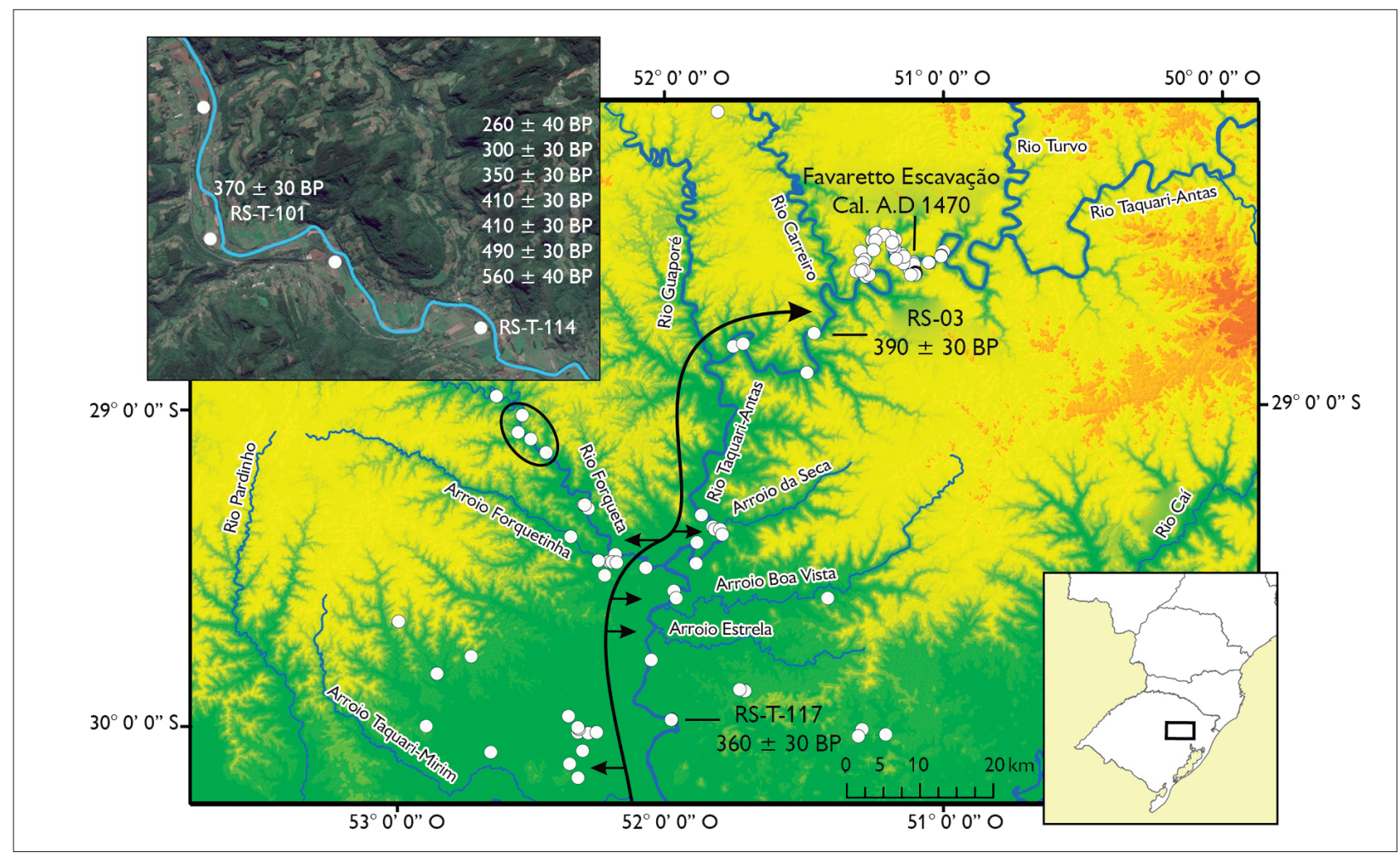

Figura 6. Localização dos sítios Guarani datados em ${ }^{14} \mathrm{C}$ para a Bacia do Taquari/Antas.

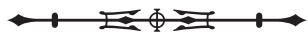


Brochado (1984, 1989) e Noelli (1993). Tal dinâmica ficou mais evidente a partir dos resultados cronológicos obtidos entre o sítio RS-T-114 e o sítio RS-T-101. Inseridos em um intenso contexto arqueológico onde se observa, como visto na Figura 6, o estabelecimento subsequente de quatro sítios Guarani nas planícies do Rio Forqueta, RS-T-122, RS-T-101, RS-T-110 e RS-T-114, a data de 370 \pm 30 BP obtida para o sítio RS-T-101 demonstrou-se contemporânea à data $350 \pm 30$ BP obtida para o sítio RS-T-114. Distantes cinco quilômetros entre si, as datas convergentes entre esses sítios, assim como a presença de datas posteriores para o RS-T-114 e o fato de não se ter encontrado indícios de abandono durante o seu processo de ocupação, indicaram que, enquanto algumas levas humanas teriam saído para o estabelecimento de um novo assentamento, possivelmente em direção ao sítio RS-T101, o sítio RS-T-114 continuou ocupado, permitindo-se pensar que, no contexto do Rio Forqueta, a expansão de sedes dentro do território de domínio teria ocorrido sem que as aldeias mais antigas fossem abandonadas, em um modelo compulsório como visto no 'enxameamento' de Brochado (1984, 1989). Uma vez que todos os sítios datados da Bacia encontram correspondência com o quadro cronológico sistemático estabelecido para o sítio RS-T-114, o modelo de ocupação compulsória do Rio Forqueta pode ser estendido para as outras áreas da Bacia.

O resultado observado na Bacia do Taquari/Antas não parece apresentar-se deslocado de uma tendência macrorregional de ocupação Guarani, uma vez que, como exposto acima, o 'enxameamento' de Brochado (1984, 1989) também foi encontrado na análise espacial e cronológica ampla apresentada por Bonomo et al. (2015). Além disso, o pulso inicial de expansão seguido de um momento de estabilidade observado pelos mesmos autores para as ocupações Guarani parece apresentar reflexos na dinâmica de ocupação da Bacia. Sendo assim, os primeiros 100 anos de ocupação, entre os séculos XIV e XV, sugerem um pulso inicial de ocupação e expansão, quando os limites do perímetro Guarani teriam sido atingidos na Bacia. As ocupações longas e contínuas das aldeias denunciam, por outro lado, um segundo momento de ocupação, inserindo-se então como um período de estabilidade secular e manutenção dos assentamentos. Durante esse momento, as datações indicam que os deslocamentos para o nordeste, norte e noroeste teriam cessado. Embora uma motivação geográfica para a pausa do avanço Guarani às terras altas possa ser pensada como hipótese de trabalho, as altitudes mais elevadas não parecem ter representado, como assinalado por De Souza et al. (2016), uma barreira para a expansão Guarani. Duas outras motivações foram então pensadas para esse processo na região do estudo.

Assim como previsto por Noelli (1993, 1998b), o controle ecológico exercido pelos Guarani aparenta ter um papel protagonista no processo de estabilidade e longa duração dos assentamentos. A longa e contínua ocupação teria sido possível a partir de constantes manejos agroflorestais sobre o espaço ocupado, contribuindo para que não ocorresse escassez de recursos naturais nas áreas próximas às aldeias. Para além da introdução dos cultivos de roça, que por si só já representavam uma importante modificação fitossociológica do ambiente nativo, a capacidade de alterar comunidades arbóreas com a multiplicação arbitrária de plantas, ou seja, a criação de florestas antropogênicas, não somente proporcionaria recursos úteis, mas também promoveria a diminuição da exploração das florestas primárias. Nessa dinâmica, se por um lado a ocupação de longa permanência era permitida pela transformação consciente do ambiente, por outro, a estabilidade também se apresentava como um efeito colateral do manejo agroflorestal, uma vez que este demandava um longo e laborioso tempo de execução. Além das questões ecológicas, a ocupação compulsória das terras baixas da Bacia poderia encontrar uma explicação também na forma de um controle político do território. Nessa lógica, durante o pulso inicial de expansão, as fronteiras Guarani teriam sido delimitadas com a inserção de aldeias em todas as áreas do perímetro ocupado, talvez 
organizando o que se entende como um guârá. Essas aldeias apresentariam fatores de alta permanência como um reflexo do manejo e das transformações ecológicas empreendidas, mas também poderiam se constituir como uma estratégia de controle do território e de delimitação das fronteiras. Tal estabilidade territorial teria sido ceifada, por fim, pela insurgência europeia na região.

\section{CONCLUSÃO}

A partir dos resultados obtidos, foi possível observar, em primeiro lugar, que a ocupação Guarani na Bacia do Taquari/Antas ocorreu em um perímetro centro-sul de várzeas que circundam áreas mais altas, não ultrapassando 400 metros de altitude. Essa porção insere-se em uma área de fronteira geomorfológica entre o Planalto das Araucárias, com a presença de Floresta Ombrófila Mista, e a Depressão Central Gaúcha, com Floresta Estacional Decidual e Semidecidual. Nesse perímetro, a presença Guarani na Bacia fez parte de um amplo contexto de ocupação das várzeas do Brasil meridional, em uma faixa de ocupação que partiu do oeste para o leste. Durante o último estágio de expansão Guarani, a partir do século XIV, possivelmente em uma conexão entre o Rio Jacuí e o Rio Taquari/Antas, no sul da Bacia, teria se iniciado a ocupação Guarani na região de estudo. A cronologia estabelecida demonstrou a possibilidade de uma ocupação regional longa, de até cinco séculos, assim como indicou que os sítios datados no sul, no centro e no norte do perímetro tiveram atividades contemporâneas, permitindo pensarse em uma característica compulsória de ocupação. O estudo cronológico sistemático realizado no sítio RS-T114 demonstrou que não somente a região foi ocupada de forma longa, mas também o contexto desse sítio, obtendo-se uma ocupação contínua de mais de três séculos para a mesma camada arqueológica. A desocupação dos sítios, por sua vez, parece ter ocorrido especialmente durante o século XVII, ao mesmo tempo em que jesuítas e bandeirantes adentravam nas porções florestadas da Bacia do Taquari/Antas, não se descartando, porém, a possibilidade da presença de aldeias Guarani ainda no final do século XVIII em partes da região.

A ocupação compulsória, a permanência nas aldeias e a longa duração regional estimulariam o aumento demográfico e as consequentes expansões territoriais para áreas novas. Como um efeito contínuo, Lathrap (1970) e Brochado $(1984,1989)$ entendem que o aumento demográfico, lento e gradual, alimentaria permanentemente a expansão ao longo dos cursos de rios com várzeas extensas. Para a Bacia, entretanto, os resultados parecem indicar que o padrão de ocupação não foi necessariamente gradual, apresentando-se em dois momentos distintos, sendo o primeiro um pulso inicial de expansão e o segundo um longo momento de estabilidade, denunciando uma complexa dinâmica espacial Guarani para a Bacia do Taquari/Antas. Em uma tentativa de interpretar tal dinâmica conjectura-se que a barreira geográfica, isto é, as altitudes elevadas, não explicaria sozinha a pausa da expansão territorial, tampouco a permanência longa e contínua em uma mesma região. Certamente o domínio do território passaria também por um controle consciente do ambiente, constituindo o poder criativo das populações Guarani diante dos espaços verdes uma poderosa estratégia de manutenção dos assentamentos. Dessa forma, se por um lado o manejo ecológico proporcionaria um maior tempo de permanência nos espaços, por outro também exigiria que as ocupações passassem por momentos de estabilidade, visto que o manejo demandaria um intenso investimento de tempo. Por fim, é possível inserir a ocupação compulsória das terras baixas da Bacia do Taquari/Antas também como uma estratégia de controle territorial, configurando-se o estabelecimento das aldeias em todos os espaços do perímetro de ocupação como uma forma consciente de manutenção política do espaço ocupado.

\section{AGRADECIMENTOS}

Os autores agradecem ao Conselho Nacional de Desenvolvimento Científico e Tecnológico (CNPq), à 
Coordenação de Aperfeiçoamento de Pessoal de Nível Superior (CAPES) e ao Centro Universitário UNIVATES, financiadores desta pesquisa por meio de editais e bolsas de estudo.

\section{REFERÊNCIAS}

ALMEIDA, Fernando Ozório de; NEVES, Eduardo Góes. Evidências Arqueológicas para a Origem dos Tupi-Guarani no leste da Amazônia. Mana, Rio de Janeiro, v. 21, n. 3, p. 499-525, dez. 2015. DOI: http:// dx.doi.org/10.1590/0104-93132015v21n3p499.

ANGRIZANI, Rodrigo Costa. La casa, La roza y el bosque: sobre los significados de la diversidade arqueológica en la subcuenca del río Santo Cristo (Noroeste de rio Grande do Sul, Brasil). Arqueologia Suramericana, Catamarca, v. 5, n. 1, p. 21-41, enero 2009.

BARTH, Fredrik. Grupos étnicos e suas fronteiras. In: POUTIGNAT, Philippe; STREIFF-FENART, Jocelyne. Teorias da etnicidade: seguido de Grupos Étnicos e suas fronteiras de Fredrik Barth. São Paulo: Editora Unesp, 1998. p. 187-227.

BONOMO, Mariano; ANGRIZANI, Rodrigo Costa; APOLINAIRE, Eduardo; NOELLI, Francisco da Silva. A model for the Guarani expansion in the La Plata Basin and littoral zone of southern Brazil. Quaternary International, Estados Unidos, v. 356, p. 54-73, Jan. 2015. DOI: http://dx.doi.org/10.1016/j.quaint.2014.10.050.

BROCHADO, José Joaquim. Proenza. A expansão dos Tupi e da cerâmica da Tradição Policrômica Amazônica. Dédalo, São Paulo, v. 27, p. 65-82, 1989.

BROCHADO, José Joaquim Proenza. An ecological model of the spread of pottery and agriculture into Eastern South America. 1984. $507 \mathrm{f}$. Thesis (Doctorate in Anthropology) - University of Illinois, Urbana-Champaign, 1984.

BROCHADO, José Joaquim Proenza. Migraciones que difundiéron la Tradición Alfarera Tupiguarani. Relaciones, México, v. 7, p. 7-39, 1973.

CADASTRO NACIONAL DE SÍTIOS ARQUEOLÓGICOS; INSTITUTO DO PATRIMÔNIO HISTÓRICO E ARTÍSTICO NACIONAL (CNSA; IPHAN). Sistema de gerenciamento do patrimônio arqueológico. Site. c2014. Disponível em: <http:// portal.iphan.gov.br/pagina/detalhes/236/> . Acesso em: 20 nov. 2015.

CHMYZ, Igor; SGANZERLA, Eliane Maria; VOLCOV, Jonas Elias; BORA, Eloi; CECCON, Roseli Santos. A arqueologia da área da LT 750kV Ivaiporã-Itaberá III, Paraná - São Paulo. Arqueologia, Curitiba, v. 5, p. 1-305, 2008. Número especial.

CHMYZ, Igor (Coord.). Relatório das pesquisas arqueológicas realizadas na área da Usina Hidrelétrica de Salto Santiago (1979-80). Curitiba: Eletrosul, IPHAN, 1981. (Projeto Arqueológico Santiago)
CHMYZ, Igor. Terminologia arqueológica brasileira para cerâmica. Curitiba: CEPA/UFPR, 1969. (Manuais de Arqueologia, 1, parte 2).

CORRÊA, Ângelo Alves. Pindorama de mboîa e îakaré: continuidade e mudança na trajetória das populações Tupi. 2014. 462 f. Tese (Doutorado em Arqueologia) - Universidade de São Paulo, São Paulo, 2014.

CORTELETTI, Rafael. Patrimônio arqueológico de Caxias do Sul. Porto Alegre: Nova Prova, 2008.

DE SOUZA, Jonas Gregorio; CORTELETTI, Rafael; ROBINSON, Mark; IRIARTE, José. The genesis of monuments: resisting outsiders in the contested landscapes of southern Brazil. Journal of Anthropological Archaeology, Amsterdam, v. 41, p. 196-212, Mar. 2016.

DIAS, Adriana Schmidt. Sistemas de assentamento e estilo tecnológico: uma proposta interpretativa para a ocupação précolonial do Alto Vale do Rio dos Sinos, Rio Grande do Sul. 2003. 401 f. Tese (Doutorado em Arqueologia) - Universidade São Paulo, São Paulo, 2003.

EREMITES DE OLIVEIRA, Jorge. Cultura material e identidade étnica na arqueologia brasileira: um estudo por ocasião da discussão sobre a tradicionalidade da ocupação Kaiowá da terra indígena Sucuri'y. Sociedade e Cultura, Goiânia, v. 10, n. 1, p. 95-113, jan.-jun. 2007. DOI: http://dx.doi.org/10.5216/sec.v10i1.1723.

FIEGENBAUM, Jones. Um assentamento Tupiguarani no Vale do Taquari/RS. 2009. 221 f. Dissertação (Mestrado em História) Universidade do Vale do Rio dos Sinos, São Leopoldo, 2009.

FUNDAÇÃO ESTADUAL DE PROTEÇÃO AMBIENTAL HENRIQUEE LUIZ ROESSLER (FEPAM). Qualidade ambiental: região hidrográfica do Guaíba, 2016. Disponível em: < http://www. fepam.rs.gov.br/qualidade/qualidade_taquari_antas/taquariantas. asp >. Acesso em: 20 fev. 2016.

GOLDMEIER, Valter Augusto (Org.). Sítios arqueológicos do Rio Grande do Sul: fichas de registro existentes no Instituto Anchietano de Pesquisas. São Leopoldo: IAP, 1983.

JONES, Siân. The archaeology of ethnicity: constructing identities in the past and present. London: Routledge, 1997.

JUSTUS, Jarbas de Oliveira; MACHADO, Maria Lídia de Abreu; FRANCO, Maria do Socorro Moreira. Geomorfologia. In: INSTITUTO BRASILEIRO DE GEOGRAFIA E ESTATÍSTICA(IBGE). Folha SH. 22 Porto Alegre e parte das folhas SH. 21 Uruguaiana e SI. 22 Lagoa Mirim: geologia, geomorfologia, pedologia, vegetação, uso potencial da terra. Rio de Janeiro: IBGE, 1986. p. 313-404. (Levantamento de Recursos Naturais, 33).

KLAMT, Sérgio Celio. Uma contribuição para o sistema de assentamento de um grupo horticultor da Tradição Cerâmica Tupiguarani. Santa Cruz do Sul: EDUNISC, 2005. 
KLAMT, Sergio Celio; LEAL, Fernando G.; DREBEL, Marione S.; BRANDT, Helena; GONÇALVES, A. C. Levantamentos arqueológicos na região de Cerro dos Bois, Venâncio Aires, RS. Revista do CEPA, Santa Cruz do Sul, v. 22, n. 27-28, p. 87-99, 1998.

KREUTZ, Marcos Rogério. Movimentações de populações Guarani, séculos XIII ao XVIII - Bacia Hidrográfica do Rio Taquari, Rio Grande do Sul. 2015. 330 f. Tese (Doutorado em Ambiente e Desenvolvimento) - Centro Universitário Univates, Lajeado, 2015.

KREUTZ, Marcos Rogério; SANTOS, Paula dos; MACHADO, Neli Galarce; LAROQUE, Luis Fernando. Colonização Guarani nas planícies do Taquari, Rio Grande do Sul, Brasil. Tellus, Campo Grande, v. 14, n. 27, p. 33-66, jul.-dez. 2014.

KREUTZ, Marcos Rogério. O contexto ambiental e as primeiras ocupações humanas no Vale do Taquari, Rio Grande do Sul. 2008. 150 f. Dissertação (Mestrado em Ambiente e Desenvolvimento) Centro Universitário Univates, Lajeado, 2008.

LA SALVIA, Fernando; BROCHADO, José Proenza. Cerâmica Guarani. Porto Alegre: Posenato Arte e Cultura, 1989.

LATHRAP, Donald W. The Upper Amazon. New York: Praeger, 1970.

MACHADO, Ademir José. Avançar, adaptar e permanecer: a Tradição Tupiguarani no Médio Rio das Antas. 2008. 213 f. Dissertação (Mestrado em História) - Universidade do Vale do Rio dos Sinos, São Leopoldo, 2008.

MACHADO, Ademir José. Dinâmica dos grupos humanos préhistóricos em áreas geobiológicas distintas: o Vale do Taquari, RS, como estudo de caso. 2003. 70 f. Trabalho de Conclusão de Curso (Graduação em História) - Universidade de Santa Cruz do Sul, Santa Cruz do Sul, 2003.

MARTIUS, Karl Friedrich Philipp von. Beitrãge zur Ethographie und Sprachangenkunde Südamerika's zumals Brasiliens. Leipzig: Friederich Fleischer, 1867.

MEGGERS, Betty Jane. Climatic oscillation as a factor in the prehistory of Amazonia. American Antiquity, Washington, v. 44, n. 2, p. 252266, Apr. 1979. DOI: http://dx.doi.org/10.2307/279075.

MEGGERS, Betty Jane. Vegetation fluctuation and prehistoric cultural adaptations in Amazonia: some tentative correlations. World Archaeology, United States, v. 8, n. 3, p. 287-303, Feb. 1977.

MEGGERS, Betty Jane. Application of the biological model of diversification to cultural distributions in Tropical Lowland South America. Biotrópica, Lawrence, v. 7, n. 3, p. 141-161, Sept. 1975. DOI: http://dx.doi.org/10.2307/2989620.

MEGGERS, Betty Jane. Prehistoric America. Chicago: Aldine Publishing Press, 1972. DOI: http://dx.doi.org/10.11606/issn.23169036.v0i44p218-269.
MEGGERS, Betty Jane; EVANS, Clifford. A reconstituição da préhistória amazônica: algumas considerações teóricas. In: O Museu Goeldi no ano do Sesquicentenário. Belém: Museu Paraense Emílio Goeldi, 1973. p. 51-69. (Publicações Avulsas, 20).

MELIÀ, Bartomeu. El Guaraní conquistado y reducido. Asunción: CEADUC, 1986.

MELLO, Antônio Augusto Souza; KNEIP, Andreas. Diálogo Linguística - Arqueologia: origem e dispersão dos povos Tupi-Guarani. In: CONGRESSO DA SOCIEDADE DE ARQUEOLOGIA BRASILEIRA, 13., 2005. Campo Grande. Anais... Campo Grande: Ed. Oeste, 2005. 1 CD-ROM.

METRÁUX, Alfred. Migrations historiques des Tupi-guarani. Journal de la Societé de Américanistes, Paris, v. 19, n. 1, p. 1-45, 1927.

MILDER, Saul Eduardo Seiguer. Arqueologia do Sudoeste do Rio Grande do Sul: uma perspectiva geoarqueológica. 2000. 187 f. Tese (Doutorado em Arqueologia) - Universidade de São Paulo, São Paulo, 2000.

MILHEIRA, Rafael Guedes. Arqueologia Guarani no Litoral SulCatarinense: história e território. 2010. 224 f. Tese (Doutorado em Arqueologia) - Universidade de São Paulo, São Paulo, 2010.

MILHEIRA, Rafael Guedes. Território e estratégia de assentamento Guarani na Planície Sudoeste da Lagoa dos Patos e Serra do Sudeste - RS. 2008. 224 f. Dissertação (Mestrado em Arqueologia) - Universidade de São Paulo, São Paulo, 2008.

MILHEIRA, Rafael Guedes; DEBLASIS, Paulo. Tupi-Guarani archaeology in Brazil. In: SMITH, Claire (Ed.). Encyclopedia of Global Archaeology. Nova York: Springer, 2014. p. 7384-7389.

MONTOYA, Antonio Ruyz de. Tesoro de la lengua Guarani. Madrid: Iuan Sanches, 1639.

MOTTA, Lisiane da. Patrimônio arqueológico de Montenegro/ RS: dialogando com a Arqueologia e o compromisso social. 2011. 311 f. Dissertação (Mestrado em História) - Pontifícia Universidade Católica do Rio Grande do Sul, Porto Alegre, 2011.

NEVES, Eduardo Góes. El Formativo que nunca terminó: la larga historia de estabilidad en las ocupaciones humanas de la Amazonía central. Boletín de Arqueología PUCP, Lima, n. 11, p. 117-142, 2007.

NEVES, Walter Alves; BERNARDO, Danilo Vicensotto; OKUMURA, Mercedes; ALMEIDA, Tatiana Ferreira de; STRAUSS, André Menezes. Origem e dispersão dos Tupiguarani: o que diz a morfologia craniana? Boletim do Museu Paraense Emílio Goeldi. Ciências Humanas, Belém, v. 6, n. 1, p. 95-122, jan.-abr. 2011. DOI: http://dx.doi.org/10.1590/S1981-81222011000100007.

NOELLI, Francisco da Silva. La distribucion geográfica de las evidencias arqueológicas Guarani. Revista de Indias, Madrid, v. 64, n. 230, p. 17-34, 2004. DOI: http://dx.doi.org/10.3989/revindias.2004. i230.408. 
NOELLI, Francisco da Silva. A ocupação humana na região sul do Brasil: arqueologia, debates e perspectivas (1872-2000). Revista USP, São Paulo, v. 44, n. 2, p. 218-269, 1999.

NOELLI, Francisco da Silva. The Tupi: explaining origin and expansion in terms of Archaeology and Historical Linguistics. Antiquity, Cambridge, v. 72, n. 277, p. 648-663, Sept. 1998a. DOI: https:// doi.org/10.1017/S0003598X00087068.

NOELLI, Francisco da Silva. Aportes históricos e etnológicos para o reconhecimento da classificação Guarani de comunidades vegetais no século XVII. Fronteiras: Revista de História, Campo Grande, v. 2, n. 4, p. 275-296, sem. 1998b.

NOELLI, Francisco da Silva. As hipóteses sobre o centro de origem e rotas de expansão dos Tupi. Revista de Antropologia, São Paulo, v. 39, n. 2, p. 7-53, 1996. DOI: http://dx.doi.org/10.11606/21790892.ra.1996.111642.

NOELLI, Francisco da Silva. Sem Tekohá não há Tekó: em busca de um modelo etnoarqueológico da aldeia e da subsistência Guarani e sua aplicação a uma área de domínio no delta do Rio Jacuí-RS. 1993. 609 f. Dissertação (Mestrado em História Ibero-Americana) - Pontifícia Universidade Católica do Rio Grande do Sul, Porto Alegre, 1993.

PARELLADA, Cláudia Inês. Estudo arqueológico no alto do vale do rio Ribeira: área do gasoduto Brasil-Bolívia, trecho X, Paraná. 2005. 271 f. Tese (Doutorado em Arqueologia) - Universidade de São Paulo, São Paulo, 2005.

PESTANA, Marlon Borges. A tradição ceramista Tupiguarani na planície costeira central do Rio Grande do Sul, Brasil. Cadernos do LEPAARQ, Pelotas, v. 8, n. 15-16, p. 83-111, 2011.

PROUS, André. Arqueologia brasileira. Brasília: Ed. UnB, 1992. $613 \mathrm{p}$.

RELLY, Eduardo; MACHADO, Neli Teresinha Galarce; SCHNEIDER, Patrícia. Do Taiaçuapé a Colinas. Lajeado: Ed. UNIVATES, 2008.

RIBEIRO, Pedro Augusto Mentz. Arqueologia do Vale do Rio Pardo, Rio Grande do Sul, Brasil. Biblos, Rio Grande, v. 7, p. 9-87, 1995.

RIBEIRO, Pedro Augusto Mentz. Arqueologia do Vale do Rio Pardo, Rio Grande do Sul, Brasil. 1991. 654 f. Tese (Doutorado em História) - Pontifícia Universidade Católica do Rio Grande do Sul, Porto Alegre, 1991.

RIBEIRO, Pedro Augusto Mentz; KLAMT, Sérgio Celio; BUCHAIM, Joaquim Jorge Silveira; RIBEIRO, Catharina Torrano. Levantamentos arqueológicos na encosta do planalto entre os vales dos Rios Taquari e Caí. Revista do CEPA, Santa Cruz do Sul, v. 16, n. 19 , p. 49-89, 1989.

RODRIGUES, Aryon Dall'Igna. A classificação do tronco linguístico Tupí. Revista Brasileira de Linguística Antropológica, Brasília, v. 3 , n. 2, p. 197-203, 2011.
RODRIGUES, Aryon Dall'Igna. A classificação do tronco lingüístico Tupí. Revista de Antropologia, São Paulo, v. 12, n. 1-2, p. 99-104, 1964.

ROGGE, Jairo Henrique. Fenômenos de fronteira: um estudo das situações de contato entre os portadores das tradições cerâmicas pré-históricas no Rio Grande do Sul. 2004. 241 f. Tese (Doutorado em História) - Universidade do Vale do Rio dos Sinos, São Leopoldo, 2004.

ROGGE, Jairo Henrique. Adaptação na floresta subtropical: a tradição Tupiguarani no Médio Rio Jacuí e no Rio Pardo. São Leopoldo, 1996. p. 3-156. (Documentos. Arqueologia do Rio Grande do Sul, n. 6).

ROSA, Alexandre Nunes da. Estudo de Impacto Ambiental: EIA referente às obras de duplicação da Rodovia BR-386/RS, segmento km 350,8 - km 386: Apêndice III. Brasília, DF: MRS Estudos Ambientais, 2009. v. 2.

SCATAMACCHIA, Maria Cristina Mineiro. A Tradição Policrômica no Leste da América do Sul evidenciada pela ocupação Guarani e Tupinambá: fontes arqueológicas e etnohistóricas. 1990. 267 f. Tese (Doutorado em Arqueologia) - Universidade de São Paulo, São Paulo, 1990.

SCHIAVETTO, Solange Nunes de Oliveira. A arqueologia Guarani: construção e desconstrução da identidade indígena. São Paulo: Annablume/Fapesp, 2003.

SCHMITZ, Pedro Ignácio. Migrantes da Amazônia: a Tradição Tupiguarani. In: KERN, Arno Alvarez (Org.). Arqueologia préhistórica do Rio Grande do Sul. Porto Alegre: Mercado Aberto, 1991. p. 295-330.

SCHMITZ, Pedro Ignácio. "Território de domínio" em grupos Tupiguarani: considerações sobre o Médio e Alto Jacuí, RS. Boletim do MARSUL, Taquara, n. 3, p. 45-52, nov. 1985.

SCHMITZ, Pedro Ignácio; ARTUSI, Lúcia; JACOBUS, André Luiz; GAZZANEO, Marta; ROGGE, Jairo Henrique; MARTIN, Hardy E.; BAUMHARDT, Gastão. Uma aldeia Tupiguarani. Projeto Candelária, RS. São Leopoldo, 1990. 135p. (Documentos. Arqueologia do Rio Grande do Sul, n. 4).

SCHNEIDER, Fernanda. Interpretação do espaço Guarani: um estudo de caso no sul da Bacia Hidrográfica do Rio Forqueta, Rio Grande do Sul, Brasil. 2014. 220 f. Dissertação (Mestrado em Ambiente e Desenvolvimento) - Centro Universitário Univates, Lajeado, 2014.

SOARES, André Luís Ramos. Pelo fim do Frankenstein Guarani. Diálogos, Maringá, v. 16, n. 2, p. 767-790, 2012. DOI: http://dx.doi. org/10.4025/dialogos.v16i2.578.

SOARES, André Luís Ramos. Contribuição para a Arqueologia Guarani. 2004. 234 f. Tese (Doutorado em Arqueologia) Universidade de São Paulo, São Paulo, 2004. 
SOARES, André Luís Ramos. Arqueologia, história e etnografia: o denominador Guarani. Revista de Arqueologia, São Paulo, v. 14-15, p. 97-114, 2001-2002.

SOARES, André Luís Ramos. Guarani: organização social e arqueologia. Porto Alegre: EDIPUCRS, 1997. (Coleção Arqueologia, 4).

STEWARD, Julian H. (Ed.). Handbook of South American Indians. Washington: Smithsonian Institution, 1946. 7 v.

SUSNIK, Branislava. Etnohistoria de los guaranies: epoca colonial. Assuncion, Paraguay: Museu Etnográfico "Andrés Barbeiro", [19791980]. (Los aborígenes del Paraguay, 2).

TEIXEIRA, Mario Buede; COURA NETO, Augusto Barbosa; PASTORE, Ulisses; RANGEL FILHO, Antonio Lourenço Rosa. Vegetação: as regiões fitoecológicas, sua natureza e seus recursos econômicos. Estudo fitogeográfico. In: INSTITUTO BRASILEIRO DE GEOGRAFIA E ESTATISTICA (IBGE). Folha SH. 22 Porto Alegre e parte das folhas SH. 21 Uruguaiana e SI. 22 Lagoa Mirim: geologia, geomorfologia, pedologia, vegetação, uso potencial da terra. Rio de Janeiro: IBGE, 1986. p. 541-632. (Levantamento de Recursos Naturais, 33).
VICROSKI, Fabricio José Nazzari; TROMMER THADDEU, Vera Lúcia. Diagnóstico do patrimônio cultural na área de pavimentação da rodovia rs 311: arroio do Meio e Travesseiro/ RS. Passo Fundo: IPHAN, 12 ${ }^{\text {a }}$ SR, 2010. Relatório Final.

WERLANG, Olívia T. Museu Arqueológico do Rio Grande do Sul. 1981. 132 f. Monografia (Bacharelado em História) Universidade do Vale do Rio dos Sinos, São Leopoldo, 1981.

WOLF, Sidnei. Paisagens e sistemas de assentamento: um estudo sobre a ocupação humana pré-colonial na Bacia Hidrográfica do Rio Forqueta/RS. 2012. 189 f. Dissertação (Mestrado em Ambiente e Desenvolvimento) - Centro Universitário Univates, Lajeado, 2012. 
Apêndice. Sítios Guarani registrados para a Bacia do Taquari/Antas. * Todas as coordenadas estão em sistema de projeção UTM WGS 1984 e Zona 22 S.

\begin{tabular}{|c|c|c|c|c|}
\hline Sítio & Coord. L* & Coord. N & Município & Referência \\
\hline RS-27 & 412.470 & 6.751 .863 & Arroio do Meio & Goldmeier (1983) \\
\hline RS-28 & 414.025 & 6.750 .240 & Arroio do Meio & Goldmeier (1983) \\
\hline RS-29 & 414.300 & 6.749 .900 & Arroio do Meio & Goldmeier (1983) \\
\hline RS-T-113 & 411.860 & 6.748 .117 & Arroio do Meio & Kreutz (2008) \\
\hline Favaretto Esc. & 439.061 & 6.786 .850 & Bento Gonçalves & Machado (2008) \\
\hline RS-NA 21 & 445.208 & 6.787 .220 & Bento Gonçalves & Machado (2008) \\
\hline RS-NA 28 “B” & 443.613 & 6.786 .351 & Bento Gonçalves & Machado (2008) \\
\hline RS-NA 28 "A" & 443.500 & 6.786 .351 & Bento Gonçalves & Machado (2008) \\
\hline RS-NA 36 & 441.431 & 6.786 .350 & Bento Gonçalves & Machado (2008) \\
\hline RS-NA 33 & 441.579 & 6.785 .279 & Bento Gonçalves & Machado (2008) \\
\hline RS-AN 18 “D” & 441.640 & 6.785 .071 & Bento Gonçalves & Machado (2008) \\
\hline RS-AN 46 & 441.462 & 6.786 .114 & Bento Gonçalves & Machado (2008) \\
\hline RS-AN 18 “E” & 441.727 & 6.785 .028 & Bento Gonçalves & Machado (2008) \\
\hline RS-AN 18 "F" & 441.645 & 6.784 .951 & Bento Gonçalves & Machado (2008) \\
\hline RS-AN 18 "G" & 441.765 & 6.784 .925 & Bento Gonçalves & Machado (2008) \\
\hline RS-AN 18 "A" & 441.628 & 6.784 .885 & Bento Gonçalves & Machado (2008) \\
\hline RS-AN 18 "H” & 441.740 & 6.784 .864 & Bento Gonçalves & Machado (2008) \\
\hline RS-AN 18 "I" & 441.676 & 6.784 .807 & Bento Gonçalves & Machado (2008) \\
\hline RS-AN 18 "B" & 441.608 & 6.784 .791 & Bento Gonçalves & Machado (2008) \\
\hline RS-AN 18 “J” & 441.623 & 6.784 .725 & Bento Gonçalves & Machado (2008) \\
\hline RS-AN 18 "C" & 441.078 & 6.784 .670 & Bento Gonçalves & Machado (2008) \\
\hline RS-AN 19 & 440.051 & 6.786 .254 & Bento Gonçalves & Machado (2008) \\
\hline RS-AN 35 & 440.140 & 6.787 .168 & Bento Gonçalves & Machado (2008) \\
\hline RS-AN 42 & 439.061 & 6.786 .850 & Bento Gonçalves & Machado (2008) \\
\hline RS-AN 39 & 438.291 & 6.789 .990 & Bento Gonçalves & Machado (2008) \\
\hline RS-AN 38 & 437.379 & 6.790 .082 & Bento Gonçalves & Machado (2008) \\
\hline RS-AN 44 "A" & 438.528 & 6.788 .643 & Bento Gonçalves & Machado (2008) \\
\hline RS-AN 44 "B" & 438.527 & 6.789 .111 & Bento Gonçalves & Machado (2008) \\
\hline RS-AN 27 & 436.244 & 6.789 .349 & Bento Gonçalves & Machado (2008) \\
\hline RS-AN 34 & 435.990 & 6.788 .044 & Bento Gonçalves & Machado (2008) \\
\hline RS-AN 09 & 434.269 & 6.785 .237 & Bento Gonçalves & Machado (2008) \\
\hline RS-VF-03 & 434.599 & 6.785 .383 & Bento Gonçalves & CNSA e IPHAN (c2014) \\
\hline RS-1 & - & - & Bento Gonçalves & Goldmeier (1983) \\
\hline RS-2 & - & - & Bento Gonçalves & Goldmeier (1983) \\
\hline RS-58 & - & - & Bento Gonçalves & Goldmeier (1983) \\
\hline RS-NA 22 & 445.520 & 6.787 .870 & Bento Gonçalves & Machado (2008) \\
\hline
\end{tabular}


Apêndice.

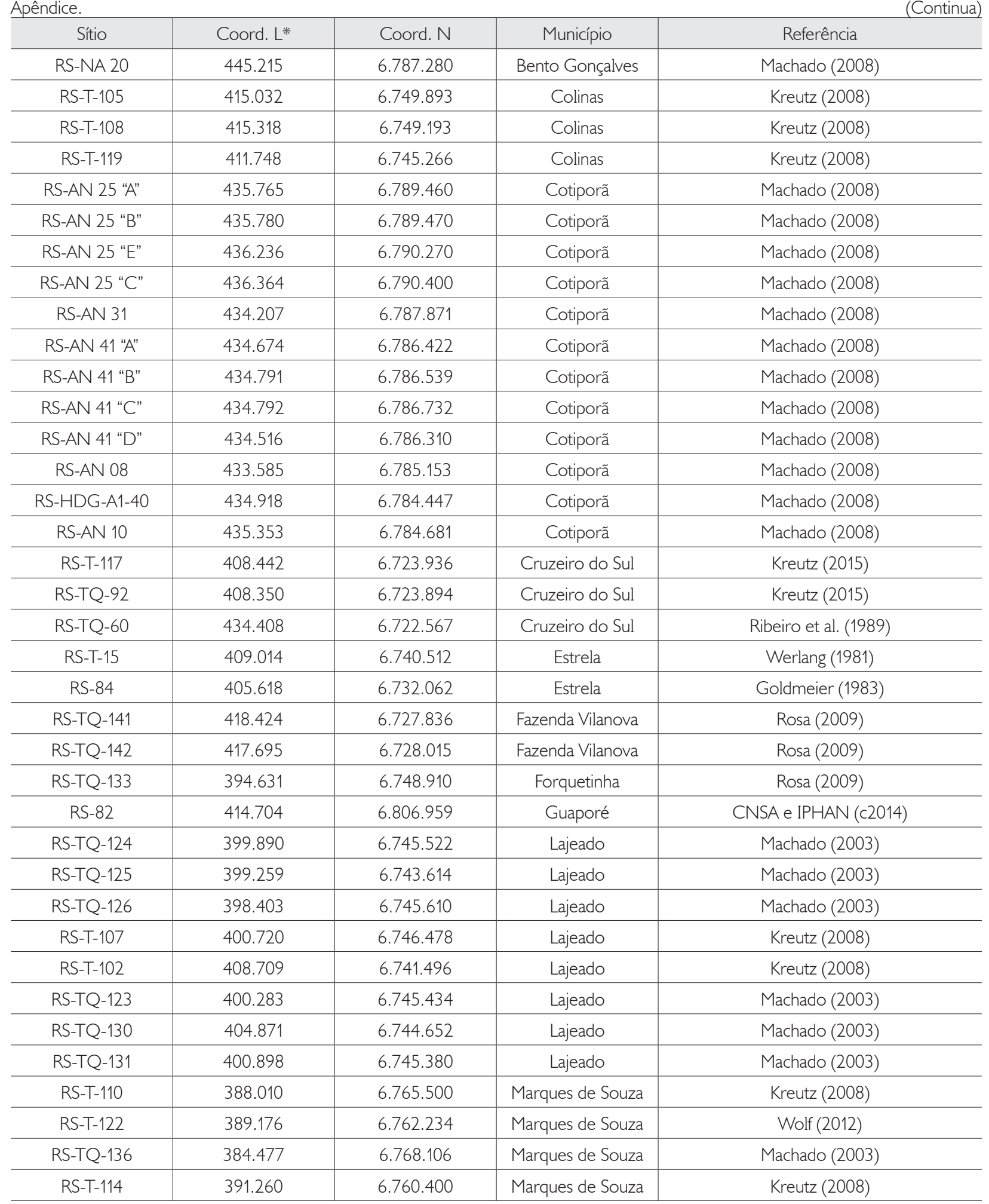


Apêndice.

\begin{tabular}{|c|c|c|c|c|}
\hline & & & & \\
\hline Sítio & Coord. L* & Coord. N & Município & Referência \\
\hline RS-T-101 & 387.436 & 6.763 .154 & Marques de Souza & Kreutz (2008) \\
\hline RS-C-38 & 437.630 & 6.721 .875 & Montenegro & Motta (2011) \\
\hline RS-03 & 427.846 & 6.776 .712 & Muçum & Goldmeier (1983) \\
\hline RS-60 & 416.830 & 6.774 .895 & Muçum & Goldmeier (1983) \\
\hline RS-61 & 426.890 & 6.771 .316 & Muçum & Goldmeier (1983) \\
\hline RS-T-124 & 418.171 & 6.775 .281 & Muçum & Kreutz (2015) \\
\hline RS-TQ-66 & 433.895 & 6.721 .635 & Tabaí & Ribeiro et al. (1989) \\
\hline RS-TQ-52 & - & - & Taquari & CNSA e IPHAN (c2014) \\
\hline JTT01 & 423.342 & 6.699 .650 & Taquari & Fiegenbaum (2009) \\
\hline RS-T-116 & 429.725 & 6.740 .515 & Teutônia & Kreutz (2008) \\
\hline TQ.RF.TR.1 & 397.014 & 6.752 .762 & Travesseiro & Vicroski e Trommer Thaddeu (2010) \\
\hline TQ.RF.TR.2 & 396.409 & 6.753 .296 & Travesseiro & Vicroski e Trommer Thaddeu (2010) \\
\hline TQ.RF.TR.3 & 396.537 & 6.753 .268 & Travesseiro & Vicroski e Trommer Thaddeu (2010) \\
\hline RS-214 & - & - & Venâncio Aires & CNSA e IPHAN (c2014) \\
\hline RS-94 & - & - & Venâncio Aires & CNSA e IPHAN (c2014) \\
\hline RS-93 & - & - & Venâncio Aires & CNSA e IPHAN (c2014) \\
\hline RS TQ 116 & 376.350 & 6.730 .193 & Venâncio Aires & Klamt et al. (1998) \\
\hline RS TQ 119 & 381.025 & 6.732 .556 & Venâncio Aires & Klamt et al. (1998) \\
\hline RS TQ 85 & - & - & Venâncio Aires & CNSA e IPHAN (c2014) \\
\hline RS TQ 86 & 396.240 & 6.719 .648 & Venâncio Aires & Klamt et al. (1998) \\
\hline RS TQ 87 & - & - & Venâncio Aires & CNSA e IPHAN (c2014) \\
\hline RS TQ 88 & 395.620 & 6.715 .967 & Venâncio Aires & Klamt et al. (1998) \\
\hline RS TQ 89 & 394.460 & 6.717 .862 & Venâncio Aires & Klamt et al. (1998) \\
\hline RS TQ 91 & 383.700 & 6.719 .450 & Venâncio Aires & Klamt et al. (1998) \\
\hline RS TQ 94 & - & - & Venâncio Aires & CNSA e IPHAN (c2014) \\
\hline RS TQ 95 & 395.620 & 6.722 .146 & Venâncio Aires & Klamt et al. (1998) \\
\hline RS TQ 96 & 395.620 & 6.722 .146 & Venâncio Aires & Klamt et al. (1998) \\
\hline RS TQ 97 & - & - & Venâncio Aires & CNSA e IPHAN (c2014) \\
\hline RS TQ 98 & 397.040 & 6.722 .071 & Venâncio Aires & Klamt et al. (1998) \\
\hline RS TQ 99 & 397.020 & 6.722 .063 & Venâncio Aires & Klamt et al. (1998) \\
\hline RS TQ 100 & 394.320 & 6.724 .374 & Venâncio Aires & Klamt et al. (1998) \\
\hline RS TQ 101 & - & - & Venâncio Aires & Klamt et al. (1998) \\
\hline RS TQ 102 & 395.710 & 6.722 .638 & Venâncio Aires & Klamt et al. (1998) \\
\hline RS TQ 103 & - & - & Venâncio Aires & CNSA e IPHAN (c2014) \\
\hline RS TQ 104 & 395.590 & 6.722 .851 & Venâncio Aires & Klamt et al. (1998) \\
\hline RS TQ 105 & 398.150 & 6.722 .173 & Venâncio Aires & Klamt et al. (1998) \\
\hline RS TQ 108 & 374.870 & 6.723 .026 & Venâncio Aires & Klamt et al. (1998) \\
\hline
\end{tabular}


Apêndice.

\begin{tabular}{c|c|c|c|c}
\hline Sítio & Coord. L* & Coord. N & Município & Referência \\
\hline RS TQ 112 & - & - & Venâncio Aires & Klamt et al. (1998) \\
\hline RS TQ 113 & - & - & Venâncio Aires & CNSA e IPHAN (c2014) \\
\hline RS TQ 135 & 371.118 & 6.737 .320 & Venâncio Aires & Machado (2008) \\
\hline RS-NA 26 "A" & 441.078 & 6.785 .036 & Veranópolis & Machado (2008) \\
\hline RS-NA 26 "B" & 440.941 & 6.785 .164 & Veranópolis & Machado (2008) \\
\hline RS-AN 24 & 439.626 & 6.787 .566 & Veranópolis & Machado (2008) \\
\hline RS AN 29 "A" & 440.140 & 6.787 .168 & Veranópolis & Machado (2008) \\
\hline RS AN 29 "B" & 439.838 & 6.787 .494 & Veranópolis & Machado (2008) \\
\hline RS AN 45 & 438.812 & 6.788 .235 & Veranópolis & Machado (2008)
\end{tabular}

